VILLACAMPA, Carolina, “Justicia restaurativa en supuestos de violencia de género en

España: situación actual y propuesta político-criminal”.

Polít. Crim. Vol. 15, No 29 (Julio 2020), Art. 3, pp. 47-75

[http://politcrim.com/wp-content/uploads/2020/05/Vol15N29A3.pdf]

\title{
Justicia restaurativa en supuestos de violencia de género en España: situación actual y propuesta político-criminal*
}

\section{Restorative Justice in gender-based violence cases in Spain: current situation and criminal policy proposal}

\author{
Carolina Villacampa \\ Catedrática de Derecho penal, Universitat de Lleida \\ carolina.villacampa@udl.cat
}

\section{Resumen}

La aprobación en España del Pacto de Estado contra la Violencia de Género en diciembre 2017 ha supuesto la confirmación de la prohibición de aplicar mecanismos de justicia restaurativa a casos de violencia de género que instituyó la Ley Orgánica de Medidas de Protección Integral contra la Violencia de Género de 2004 y ha mantenido la Ley del Estatuto de la Víctima del Delito de 2015. En este trabajo se ofrecen argumentos que parten tanto de las ventajas atribuidas a la implementación de este ideal de la justicia a estos casos, como de la situación normativa internacional y comparada, del apoyo que dicha implementación podría hallar en cierto sector del pensamiento feminista o de las evaluaciones positivas de resultados obtenidos por programas de justicia restaurativa orientados a supuestos de violencia de género para sostener la adecuación de modificar esta orientación político-criminal. Sobre esta base, se concluye proponiendo las líneas básicas que debería contener un programa de justicia restaurativa aplicable a estos supuestos.

Palabras clave: justicia restaurativa, mediación, violencia de género, pacto de estado.

\begin{abstract}
The approval in Spain of the State Agreement to Combat Gender Violence in December 2017 confirmed the prohibition of applying restorative justice mechanisms to gender violence cases of was instituted by the 2004 Organic Law on Integral Protection Measures against Gender Violence and maintained by the 2015 Law on the Statute of the Crime Victim. This paper offers reasons based on the advantages attributed to the implementation of this ideal of justice in these cases, as well as on the international and comparative normative situation, the support that such implementation could find in certain feminist academy sector or the positive evaluations of results obtained by restorative justice programs oriented to cases of gender violence in order to defend the adequacy of modifying this political-criminal orientation. On this basis, the paper concludes by proposing the basic outlines that should include a restorative justice program applicable to these cases.
\end{abstract}

Keywords: restorative justice, mediation, gender violence, state agreement.

\footnotetext{
* Este trabajo ha sido realizado en ejecución del proyecto RTI2018-094686-B-C21, financiado por el Ministerio de Ciencia, Innovación y Universidades.
} 


\section{Introducción}

En materia de violencia de género en España rige la Ley Orgánica 1/2004 (en adelante, LO 1/2004). Se trata de una norma que mantiene una aproximación muy punitivista a esta realidad que obliga a las víctimas a pasar por el sistema de justicia penal para obtener protección. ${ }^{1}$ Una de las manifestaciones más relevantes del referido punitivismo en tanto paradigma de la política criminal española en materia de violencia de género, ha comportado que la resolución de estos conflictos se haya reconducido necesariamente al empleo de la justicia retributiva, sin ofrecer margen aplicativo alguno a mecanismos de justicia restaurativa, ${ }^{2}$ pese a que los mismos se hayan mostrado adecuados para la resolución de estas situaciones en países de nuestro entorno jurídico.

La asunción en España de una política de arresto y persecución obligatorios plasmada en el necesario paso por el sistema de justicia penal para conferir protección a las víctimas tiene una de sus manifestaciones más evidentes en la prohibición de la mediación incorporada al art. 87 ter.5 de la Ley Orgánica del Poder Judicial española (en adelante, LOPJ) por obra del art. 44 LO 1/2004. ${ }^{3}$ Dicha prohibición normativamente establecida ha provocado que en España apenas se haya aplicado mediación penal en supuestos de violencia de género, ${ }^{4}$ o por lo menos, que esto no se haya hecho abiertamente. Así, más allá de los programas de mediación penal en justicia juvenil, pese a que han sido varias las experiencias de ejecución de programas de mediación penal con adultos, prácticamente ninguno de ellos ha supuesto la implementación de mecanismos de justicia restaurativa en supuestos de violencia de género. Aunque en algunos de estos programas pudiese haberse llegado a mediar en tal materia, las posibilidades de aplicación de mecanismos de justicia restaurativa en estos casos resultaron claramente entorpecidas tras la aprobación de la LO 1/2004 y la introducción en su virtud del art. 87 ter.5 LOPJ. En la práctica, dicho precepto supuso la paralización de los procesos de mediación en violencia de género que pudiesen estarse llevando a cabo en aquel momento en España. ${ }^{5}$

\footnotetext{
${ }^{1}$ Al respecto, por todos, LAURENZO COPELLO (2005), pp. 2 y ss.; LAURENZO COPELLO (2008), pp. 329 y ss.; MAQUEDA ABREU (2006), pp. 1 y ss.; MAQUEDA ABREU (2010), pp. 1 y ss.; ACALE SÁNCHEZ (2006), pp. 169 y ss.; LARRAURI PIJOAN (2007b), pp. 30 y ss.

${ }^{2}$ El concepto de justicia restaurativa, por contraposición a la retributiva, no es unívoco. Junto a las concepciones que caracterizan este paradigma de la justicia sobre la base del encuentro entre víctimas y ofensores en un ambiente favorable a su desarrollo de un papel activo en la discusión y la toma de decisiones, las hay que pivotan sobre la idea reparativa - conforme a la cual se trata de un ideal de justicia que persigue que el daño que el delito ha causado a las personas y las relaciones sean reparadoso las que adoptan el denominado concepto transformativo. Con todo, siguiendo a Eglash, puede identificarse con un modelo de justicia que ofrece una oportunidad a todas las partes involucradas para reparar la relación, así como al infractor de reparar el daño causado. Sobre sus distintas conceptuaciones, entre otros, véase VILLACAMPA ESTIARTE et al. (2019), pp. 197-199.

${ }^{3}$ En el art. 87 ter.5 LOPJ, al regular la competencia de los Juzgados de Violencia sobre la Mujer, se dispone "en todos estos casos está vedada la mediación".

4 La mediación penal, también conocida como mediación víctima-ofensor, constituye uno de los instrumentos de los que se vale la justicia restaurativa. Generalmente implica la intervención de la víctima, del victimario y de uno o dos mediadores. Consiste en uno o varios encuentros entre las partes afectadas por un conflicto (constitutivo de infracción penal) en que una persona neutral, independiente e imparcial (el mediador o facilitador) asiste a las partes en el proceso de entender las causas reales que propiciaron la producción de la infracción y a comprender las consecuencias de la misma para alcanzar un acuerdo que repare, material y simbólicamente, el daño causado. Acerca de este concepto, véase, VILLACAMPA ESTIARTE et al.(2019), pp. 200-201.

${ }^{5}$ GUARDIOLA LAGO (2009), p. 18, se refiere a que tal circunstancia paralizó los procesos que se estaban llevando a cabo, por ejemplo, en Cataluña.
} 


\section{Polít. Crim. Vol. 15, No 29 (Julio 2020), Art. 3, pp. 47-75 \\ [http://politcrim.com/wp-content/uploads/2020/05/Vol15N29A3.pdf]}

La aprobación de dicha norma condujo a la doctrina a afirmar de forma mayoritaria que, efectivamente, la implementación de mecanismos de justicia restaurativaconcretamente de la mediación penal - había dejado de ser normativamente posible en supuestos de violencia de género entre íntimos en nuestro ordenamiento jurídico. ${ }^{6}$ Parecía, pues, clara la voluntad de nuestro legislador de evitar la posible aplicación de tales procedimientos a estos supuestos. Sin embargo, pronto se ensayaron interpretaciones restrictivas del precepto, como apuntar que la prohibición de mediación en estos casos solo afectaría a la de carácter civil, pero no a la penal, ${ }^{7}$ o que, siendo aplicable a supuestos de mediación penal, no prohibiría la producida tras la fase de instrucción o la concerniente a supuestos de violencia familiar que no fuesen de género. ${ }^{8}$

Sin embargo, la ausencia de la aplicación de mecanismos de justicia restaurativa a estas manifestaciones de la conducta violenta, como después se expondrá en este trabajo, ha privado a las víctimas de este fenómeno de las ventajas que este paradigma de la justicia puede comportarles. Además, sitúa a España en una posición que comienza a resultar normativamente singular respecto de la de otros países de nuestro entorno jurídico, que paulatinamente han ido admitiendo la implementación de mecanismos de justicia restaurativa en supuestos de violencia de género. De futuro, pues, también en este país resultaría adecuado que se revisase la referida prohibición legal y se normase sobre este particular, razón por la que en estas páginas se propone cuál debería ser el contenido básico de un programa restaurativo aplicable a supuestos de violencia de género.

\section{Implementación de programas de justicia restaurativa en España pese a la ausencia de regulación}

La prohibición legal de la mediación en supuestos de violencia de género en este país debe encuadrarse en un contexto más amplio de absoluta ausencia de interés del legislador español por la mediación o por otros instrumentos para actuar el ideal de justicia restaurativa con carácter general. No ha sido hasta la aprobación de la Ley 4/2015, mediante la que se transpone la Directiva 2012/29/UE, cuando ha comenzado a legislarse en España en materia de mediación. La mediación penal ante y tras sentencia tiene reconocimiento normativo en la justicia penal de menores desde el año 2000, pero en la de adultos no ha sido normativamente reconocida hasta la aprobación de la referida Ley 4/2015. Antes de ese momento, la todavía vigente Ley de Enjuiciamiento Criminal ni siquiera incluye referencia alguna a términos como la justicia restaurativa o la mediación, sin que hayan llegado a convertirse en Derecho positivo, sustituyendo a esta decimonónica ley procesal penal, ni el Anteproyecto de Ley de Enjuiciamiento Criminal de 2011 ni el borrador de Código Procesal Penal de 2013, aunque ambos, sobre todo el primero, sí contenían disposiciones referidas a los procesos de mediación intraprocesal.

\footnotetext{
${ }^{6}$ Por todos, LARRAURI PIJOAN (2007a), pp. 130 y ss.; ESQUINAS VALVERDE (2008), pp. 16-17; ESQUINAS VALVERDE (2010), pp. 325-326; BARONA VILAR (2011), p. 301; DÍAZ LÓPEZ (2011), p. 19; ALONSO SALGADO y TORRADO TARRÍO (2011), pp. 567 y ss.; VÁZQUEZ-PORTOMEÑE SEIJAS (2013), p. 313; FERNÁNDEZ LÓPEZ (2015), pp. 372 y ss.

${ }^{7}$ Véase, RODRÍGUEZ LAÍNZ (2011), pp. 5-8. Había apuntado ya esta posibilidad refiriéndose a opciones que anteriormente la sostenían, BARONA VILAR (2011), p. 301.

${ }^{8}$ Véase GUARDIOLA LAGO (2009), pp. 29 y ss. Así, por ejemplo, en Cataluña se ha mediado en casos relativos a la violencia de género cuando la instrucción no es por uno de los delitos contemplados en el art. 87 ter LOPJ -casos de impago de pensiones o quebrantamiento de condena- o en el País Vasco se ha implementado una vez concluida la fase de instrucción en el correspondiente proceso penal.
} 
Pese a la ausencia de reconocimiento legal de la aplicación de mecanismos de justicia restaurativa en España, este paradigma de la justicia comenzó a ser observado por algunos operadores jurídicos que impulsaron la implementación de proyectos piloto, aplicando programas de mediación sin apoyo normativo. Las primeras experiencias en mediación se llevaron a cabo en la Comunidad Valenciana con menores a inicios de los 90. Con adultos, ya en 1993 se aplicó en dicha Comunidad Autónoma el primer programa piloto gracias a la colaboración del Juzgado de Instrucción núm. 2 de Valencia y del servicio de atención a la víctima de dicha comunidad. ${ }^{9}$ Ya desde 1998 se viene desarrollando en Cataluña el programa de mediación y reparación penal en la jurisdicción ordinaria del Departamento de Justicia de la Generalitat, ${ }^{10}$ que constituyó el programa pionero de mediación penal con adultos en España.

A partir de esas experiencias, y de otras de mediación penal con ofensores drogodependientes realizadas en Madrid, comenzó en noviembre de 2005 a trabajarse en la puesta en funcionamiento de un proyecto piloto en mediación penal de adultos en el Juzgado Penal núm. 20 de Madrid apoyado por el Consejo General del Poder Judicial (en adelante, CGPJ). Desde ese momento, el CGPJ comenzó a extender esas experiencias piloto a otros órganos judiciales del país. El proyecto piloto impulsado por el CGPJ representó que la mediación penal se extendiera a juzgados españoles más allá de Cataluña. Posteriormente, en 2007 se creó el Servicio de Mediación Penal en Barakaldo (País Vasco), que se extendió después a Bilbao y San Sebastián en 2008, momento a partir del cual los tres territorios históricos vascos tuvieron su servicio de mediación penal.

Aun con la ausencia de regulación de cualquier aspecto relacionado con la justicia restaurativa hasta momentos bien recientes, a instancias de determinadas administraciones autonómicas (sobre todo, Cataluña y el País Vasco) y del CGPJ en el resto del estado, la implementación de la mediación penal, no así se otros instrumentos de justicia restaurativa, se ha ido ampliando a toda la geografía española.

El CGPJ ha acabado adoptando acuerdos con todas las Comunidades Autónomas para facilitar dicha activación. Originariamente los mismos fueron firmados con colegios de abogados u organizaciones asistenciales. Sin embargo, con el tiempo, la contraparte ha acabado siendo generalmente el mismo gobierno autonómico. La mayoría de estos acuerdos, cuanto menos en su última versión, datan de 2015, aunque el firmado con la Comunidad de Madrid es de 2010 y el de Aragón de 2012.

Conforme a los datos con que contaba el CGPJ en 2009, fecha en que se produjo el último balance de situación sobre mediación elaborado por el máximo órgano de gobierno judicial, el número de juzgados que hacían mediación penal con adultos era de 170 en todo el territorio del Estado. ${ }^{11}$ De ellos, el $48 \%$ se situaba en Cataluña, el $22 \%$ en el País Vasco y el 30\% distribuidos sobre todo en Andalucía, Valencia, Castilla-León y

\footnotetext{
${ }^{9}$ Véase acerca de las experiencias piloto en mediación de adultos aplicadas en España, BARONA VILAR (2011), pp. 229 y ss.; DÍAZ LÓPEZ (2011) p. 17; RÍOS MARTÍN et al. (2012), pp. 1-360. Específicamente en relación con las experiencias prácticas de mediación en la Comunidad Autónoma de La Rioja, GORDILLO SANTANA (2007), pp. 335 y ss.

${ }^{10}$ Ampliamente sobre el programa de mediación en el ámbito de la justicia penal de menores y sobre el programa de mediación penal con adultos de 1998 y el programa marco de mediación y reparación en esta Comunidad, véase MARTÍN et al. (2010), pp. 599 y ss.

${ }^{11}$ SÁEZ (dir.) (2010), pp. 18-19.
} 
Madrid. Más contemporáneamente, el número de juzgados en que se practica mediación penal con adultos, según datos de la página web del CGPJ, ha aumentado ligeramente. Ahora la practican un total de 176 juzgados y 15 audiencias provinciales. ${ }^{12}$ La mayoría de estos órganos judiciales siguen localizados en Cataluña (32), aunque no ya en una proporción tan desigual, puesto que el País Vasco y Andalucía cuentan cada uno de ellos con 30 órganos judiciales que tienen este tipo de programas, seguidos de CastillaLeón (21), Valencia (16) o Aragón (12). Junto a esto, se constata la existencia de servicios de mediación penal intrajudicial en 26 provincias españolas. ${ }^{13}$

En cuanto a datos sobre mediación penal, los primeros recogidos a nivel del territorio del Estado se remontan al balance efectuado por el CGPJ en 2009. En aquel momento, constaba como se habían derivado a mediación en el territorio de todo el Estado 1.763 asuntos, al margen de los 909 expedientes en que se había mediado en Cataluña y los 393 del País Vasco. ${ }^{14}$ Los últimos datos estadísticos que se incluyen en el portal web del CGPJ, en que se comparan los correspondientes a 2015 con los de 2014, confirman una disminución del $10 \%$ de asuntos derivados a mediación de un año respecto del otro (4.214 en 2014 frente a 3.804 en 2015) debido a la reducción de servicios a causa de la crisis económica. ${ }^{15}$ Sin embargo, las terminaciones de los procesos sin acuerdo quedaron reducidas a casi la mitad en 2015 (734 en 2014 frente a 390 en 2015), lo que debe identificarse como un éxito del sistema, puesto que el número de acuerdos alcanzado ronda el $80 \%$.

La evolución positiva de la implementación de la justicia restaurativa en España pese al silencio legal se ha evidenciado no solo a través de la activación de programas de mediación, sino también mediante la adopción de protocolos para la mediación penal con adultos. Los primeros fueron aprobados por el pleno del CGPJ en 2010. En 2013, este órgano efectuó una guía que contenía el protocolo de derivación a mediación elaborado por este órgano. En 2016, tras la aprobación de la Ley 4/2015, el CGPJ ha elaborado una segunda guía para la implantación de los servicios de mediación que contiene la referida guía junto a una versión actualizada del protocolo de derivación a mediación, sin entrar a protocolizar el posible recurso a otros instrumentos de justicia restaurativa. ${ }^{16}$

El mencionado protocolo prevé que la derivación la realice el órgano judicial—aunque finalmente sea el mediador quien decida si la misma es o no viable- mediante resolución motivada, rellenando una ficha de derivación con inclusión de unos datos mínimos sobre el caso. Cabe que la derivación se produzca en instrucción, en fase de juicio oral o incluso en ejecución de sentencia, admitiéndose en todos los delitos, salvo en los de violencia de género, siempre que el acusado no niegue su intervención en los hechos y cuando las partes lo consientan.

\footnotetext{
12 Pueden consultarse los órganos judiciales penales que la ofrecen en http://www.poderjudicial.es/cgpj/es/Temas/Mediacion/Organos-judiciales-que-ofrecenmediacion/Mediacion-Penal/.

${ }^{13}$ Véase información contenida en http://www.poderjudicial.es/cgpj/es/Temas/Mediacion/Servicios-deMediacion-Intrajudicial/Mediacion-Penal/

${ }^{14}$ SÁEZ (dir.) (2010), pp. 19-20.

${ }^{15}$ CONSEJO GENERAL DEL PODER JUDICIAL (2015a), pp. 4-5.

${ }^{16}$ CONSEJO GENERAL DEL PODER JUDICIAL (2015b), pp. 93-128.
} 
Recibida la derivación, el equipo de mediación contacta con las partes por teléfono para explicarles en qué consiste el proceso y hacer una primera sesión individual con cada una. Si estas consienten, firman el acta constitutiva de la mediación y comienza el proceso. El juez puede fijar un plazo estimado para la mediación, que debe ser flexible y puede ser ampliado. Si el proceso de mediación finaliza con acuerdo, el equipo de mediación redacta un acta de reparación, de manera que serán los abogados de las partes los que gestionen cómo se introduce el acuerdo en el proceso. Cuando la mediación se produce en instrucción, cabe que se dicte sentencia de conformidad (con reducción de la pena por aplicación de la atenuante de reparación entre otras posibles) o incluso que el proceso se transforme en proceso penal por delito leve, en cuyo caso podría acabar sobreseído si así lo solicita el fiscal. Si la mediación se hace en fase de enjuiciamiento, las partes pueden pedir al inicio del juicio que se dicte sentencia de conformidad cambiando sus respectivos escritos de acusación y defensa, pudiendo conducir el acuerdo a una reducción de la pena por la eventual aplicación de circunstancias atenuantes o a la suspensión de la ejecución de la pena de prisión. Además, el plan de reparación acordado se puede incorporar a la sentencia como forma de cumplir con la responsabilidad civil derivada del delito. Finalmente, si la derivación se produce en ejecución, el juez competente deberá tenerlo en cuenta para acordar la suspensión.

En estricta relación con la violencia de género, a pesar de la extensión paulatina de prácticas de justicia restaurativa en España, la prohibición legal de la mediación contenida en el art. 87 ter. 5 LOPJ por efecto de la LO 1/2004 ha hecho que apenas se haya mediado en estos casos. Tal efecto cortocicuitador de programas restaurativos en este ámbito, sin embargo, debe entenderse referido a los supuestos que formalmente caen bajo los dominios de la LO 1/2004, esto es, los de violencia física, psicológica o sexual aplicada por el varón contra la mujer con la que mantiene o ha mantenido una relación sentimental o contra sus descendientes. Otras formas de violencia contra las mujeres que no entren en el ámbito aplicativo de la ley no se ven afectados por la prohibición legal. Aun cuando en Cataluña se medió en casos de violencia de género entre 1998 y 2004 con resultados positivos, tales procesos restaurativos cesaron al aprobarse la LO 1/2004. Sin embargo, gracias a la interpretación restrictiva de la prohibición contenida en la LO 1/2004 que secundó el gobierno vasco, limitando su vigencia a los procedimientos que son competencia de los juzgados de violencia contra la mujer, el único ámbito territorial en el que tras 2004 se ha mediado claramente en casos de violencia de género ha sido en el País Vasco. Esto determinó que en 2008 el $14 \%$ de los 393 casos que se mediaron en Euskadi fuesen precisamente de violencia de género, incluyendo entre ellos causas por delitos de lesiones producidas por violencia de género $^{17}$.

\section{Situación normativa actual en materia de justicia restaurativa: mantenimiento de la prohibición de la mediación en casos de violencia de género}

Ya se ha indicado como materialmente se había intentado orillar la prohibición legal de mediación en casos de violencia de género antes de que la justicia restaurativa tuviese algún tipo de reconocimiento normativo en España. Sin embargo, por muy loables que hayan sido los intentos de limitar la aplicación de la disposición prohibicionista de la mediación en violencia de género contenida en el art. 87 ter LOPJ, no parece que el escenario vaya a cambiar en el futuro inmediato.

\footnotetext{
${ }^{17}$ VARONA MARTÍNEZ (2009), pp. 38-40.
} 
Ciertamente, poca esperanza existía al efecto en un contexto normativo como el español antes de 2015, año en que se aprobó la Ley del estatuto de la víctima del delito. Sin embargo, cabía pensar que dicha situación podía haber experimentado un cambio con la aprobación de dicha norma; cabía imaginar que su aprobación podía suponer un vuelco en el escenario normativo prohibicionista a la resolución alternativa de conflictos relacionados con la violencia de género delineado por la LO 1/2004. Y es que esta norma, al referirse en el art. 15 a los servicios de justicia restaurativa, reconoce por primera vez en nuestro ordenamiento jurídico la posible aplicación de mecanismos de justicia restaurativa en el marco del proceso penal de adultos, aun cuando no determine qué efectos tiene un eventual acuerdo reparador en este ${ }^{18}$.

En tal sentido, de forma bastante fiel, al menos en parte, a lo dispuesto en el art. 12 Directiva 2012/29/UE, el precepto establece los requisitos que deben cumplirse para poder acceder a un proceso de justicia restaurativa, difiriendo las condiciones de acceso a lo que se disponga reglamentariamente, aun cuando hasta el momento el desarrollo reglamentario de la norma se limita a lo que se dispone en el Real Decreto 1109/2015 (en adelante, RD 1109/2015). ${ }^{19}$ Sin embargo, esta norma de desarrollo, al margen de indicar solamente a quién corresponde la derivación de los asuntos penales a mediación, no se refiere a otros mecanismos de justicia restaurativa diversos a la mediación. ${ }^{20}$

Según el art. 15 Ley 4/2015, los requisitos previstos tienen como objeto conseguir la adecuada reparación - material y moral, indica la norma - de los perjuicios derivados del delito, contando con que los debates desarrollados en el procedimiento de mediación serán confidenciales. Tales requerimientos reflejan en su mayoría los contenidos en el art. 12 Directiva 2012/29/UE, que en puridad son los generalmente demandados por la academia en los procesos de justicia restaurativa. ${ }^{21}$ Entre ellos, el infractor debe haber reconocido los hechos esenciales de los que deriva su responsabilidad y la víctima debe haber prestado su consentimiento después de haber recibido información exhaustiva e imparcial sobre su contenido, sus posibles resultados y los procedimientos existentes para hacer efectivo su cumplimiento. Además, el procedimiento de mediación no debe

\footnotetext{
${ }^{18}$ Más allá de lo dispuesto en el art. 85 Código Penal español, en el sentido de que el juez puede condicionar la suspensión de la ejecución de la pena de prisión a que el condenado cumpla las obligaciones asumidas en virtud de un acuerdo adoptado en un proceso de mediación con la víctima, nada se dispone en la Ley de Enjuiciamiento Criminal en relación con el momento procesal en el que pueden derivarse los asuntos a mediación o los efectos que pueda tener el eventual alcance de un acuerdo en instrucción o en fase de juicio oral.

${ }^{19}$ En tal sentido, los arts. 19 y 37 RD 1109/2015 atribuyen a las oficinas de asistencia a las víctimas tanto la función de informar a las víctimas de las diferentes medidas de justicia restaurativa, como la de proponer al órgano judicial la aplicación de la mediación penal cuando se considere beneficioso para la víctima, cuanto, finalmente, realizar actuaciones de apoyo a los servicios de mediación extrajudicial, que ni el RD ni la propia Ley 4/2015 indican en qué consisten. Lo indicado es lo hasta el momento regulado reglamentariamente en lo que a las condiciones de acceso a la mediación se refiere, en que la propuesta de derivación a la mediación en el ámbito del proceso penal se atribuye a las oficinas de asistencia a la víctima sin determinación de proceso alguno. Muy crítico con esta remisión reglamentaria, TAMARIT SUMALLA (2015), p. 323.

20 Junto a la mediación víctima-ofensor, otros mecanismos de justicia restaurativa habitualmente empleados en supuestos de violencia de género y familiar son las conferencias de grupos de familia y los círculos de paz. Sobre los mismos, véase, KURKI (2003), pp. 293 y ss.; RAYE y ROBERTS (2007), pp. 211 y ss.; UMBREIT et al. (2007), pp. 528 y ss.; SHERMAN y STRANG (2007), p. 13; FERGUSON (2009), pp. 13 y ss.; BELTRÁN MONTOLIU (2009), pp. 58-59; BARONA VILAR (2011), pp. 144 y ss.; VILLACAMPA ESTIARTE (2012), pp. 195-197.

${ }^{21}$ Por todos, con carácter bastante reciente, FERNÁNDEZ LÓPEZ (2015), pp. 86 y ss.
} 
entrañar un riesgo para la seguridad de la víctima ni existir peligro de que su desarrollo pueda causar nuevos perjuicios materiales o morales a esta. Junto a estos, no requiere explícitamente el Derecho interno español que el acuerdo reparador que alcancen las partes sea voluntario, si bien dicha voluntariedad puede considerarse ínsita en la exigencia incluida en el art. 15 Ley 4/2015 de que también el infractor haya prestado su consentimiento a la intervención en el proceso, así como en la relativa a que tanto víctima como infractor pueden revocar su consentimiento para participar en el procedimiento de mediación en cualquier momento. La única exigencia suplementaria que incluye el Derecho interno español en relación con lo que dispone la Directiva consiste en que para poder derivar el caso a un proceso de mediación esta no puede estar prohibida por la ley para el delito cometido. Dado que el único supuesto de prohibición expresa es el incluido en casos de violencia de género por la LO 1/2004, cualquier atisbo de optimismo relativo a la posible admisión de la mediación en estos supuestos queda excluido.

No solo no cabe en el presente la mediación en los supuestos de violencia de género porque el art. 15.1.e) Ley 4/2015 se ha encargado de dejar claro que no se ha producido una derogación sobrevenida del art. 87 ter. 5 LOPJ en la versión que le confirió la LO $1 / 2004$, sino que no resulta previsible que este escenario normativo cambie en España en el futuro inmediato a juzgar por las medidas contempladas en el marco del Pacto de Estado contra la Violencia de Género adoptado el 27 de diciembre de 2017. Se trata de un acuerdo político de Estado firmado entre el gobierno, representantes de las comunidades autónomas y de la administración local tras haber sido consensuado por estos agentes políticos junto a asociaciones sindicales, empresariales y civiles. Se lo considera un pacto que concitó el acuerdo de la mayor parte de partidos políticos. Fue suscrito tras la tramitación conjunta de sendas proposiciones no de ley presentadas en septiembre de 2016 por los grupos parlamentarios socialista y popular en el Congreso y adoptado después de que tanto congreso como senado aprobasen los correspondientes informes sobre las medidas de todo tipo mediante las que articular el pacto, cuya vigencia va de 2018 a 2022, contando además con una dotación presupuestaria de 1.000 millones de euros.

Pues bien, en el referido contexto político de aprobación del Pacto de Estado contra la Violencia de Género, tanto el CGPJ como los expertos que desfilaron ante el congreso y el senado en punto a determinar el contenido del pacto se han afanado en sostener que la mediación penal debe seguir hallándose prohibida en supuestos de violencia de género. De tal manera que tanto en el informe elaborado por la subcomisión al efecto constituida en el seno de la Comisión de Igualdad del Congreso (medida 116) como en el de la ponencia también constituida con dicho fin en el seno de la Comisión de Igualdad del Senado se insiste en la necesidad de confirmación normativa de dicha prohibición, ya a nivel legislativo, ya en relación con los protocolos que se aprueben y revisen ${ }^{22}$.

Tal empecinamiento en mantener la prohibición in totum de la aplicación de este tipo de mecanismos en supuestos de violencia de género, cualquiera que sea la gravedad o las condiciones en que el delito se haya producido, choca frontalmente con la opinión cada vez más prevalente en la propia doctrina española. De cada vez más esta es partidaria de

${ }^{22}$ SECRETARÍA DE ESTADO DE IGUALDAD-DELEGACIÓN DEL GOBIERNO PARA LA VIOLENCIA DE GÉNERO (2019), p. 32. 
que se permita el empleo de este tipo de mecanismos en tales supuestos cuando pueda garantizarse la igualdad de las partes que intervienen en el proceso ${ }^{23}$. La referida insistencia prohibicionista es además consistente con posiciones próximas al feminismo estructural o radical de segunda ola, que ha devenido institucional, cuyas máximas representantes han sido Catharine Mackinnon en el ámbito de la teoría legal y autoras como Sandra Casey o Mary King en el del pensamiento filosófico feminista. Esta es la corriente del feminismo que ha defendido la implementación de políticas de arresto y prosecución obligatoria, así como la intervención del sistema de justicia penal de oficio en los supuestos de violencia de género ${ }^{24}$ y que ha puesto sobre todo el acento en los inconvenientes que tiene la aplicación de mecanismos de justicia restaurativa a supuestos de violencia de género. ${ }^{25}$ Que la prohibición del recurso a la justicia restaurativa en supuestos de violencia de género se deriva más del posicionamiento de base sostenido desde cierto sector del pensamiento feminista que en atención a la imposibilidad de plano de recurrir a la misma en delitos violentos en general se evidencia, entre otras razones, en que se han recurrido a este paradigma de la justicia para mediar en delitos violentos graves, como el homicidio, con resultados esperanzadores $^{26}$. E incluso en que se haya recurrido a mecanismos de justicia restaurativa en el ámbito de la justicia penal internacional para interceder en crímenes internacionales de la magnitud del genocidio o los de lesa humanidad ${ }^{27}$.

Entre las desventajas atribuidas por este feminismo institucional al recurso a la justicia restaurativa en supuestos de violencia de género, siguiendo la clasificación que en su momento propusiera Kohn ${ }^{28}$ para sintetizar su exposición, ${ }^{29}$ se cuentan, en primer lugar, las que tienen que ver con la incompatibilidad de la teoría de la justicia restaurativa con la de la violencia doméstica. Esto porque conceptos como la disculpa y la petición de

\footnotetext{
${ }^{23}$ Abiertamente proclives a la inclusión de mecanismos de justicia restaurativa en supuestos de violencia de género en la doctrina española se han mostrado, entre otros, CARMENA CASTRILLO (2005), p. 37; LARRAURI PIJOAN (2007a), pp. 131 y ss.; ESQUINAS VALVERDE (2008), pp. 85 y ss., quien desarrolla detenidamente una propuesta favorable a la inclusión de un proceso de mediación integrado en el sistema de justicia penal — no alternativo - para los casos de violencia de género manifestados en episodios esporádicos que garanticen el equilibrio de fuerzas entre autor y víctima, preservando la seguridad de la víctima, mediante un sistema de conferencias de grupos de familia; ESQUINAS VALVERDE (2010), pp. 323. En términos semejantes; GUARDIOLA LAGO (2009), pp. 1 y ss.; CASTILLEJO MANZANARES et al. (2011), pp. 38 y ss.; VILLACAMPA ESTIARTE (2012), pp. 209 y ss., en que, sobre la base de lo en aquel momento dispuesto en el Anteproyecto de Ley de Enjuiciamiento Criminal, proponía cómo podría desarrollarse un programa de justicia restaurativa en supuestos de violencia de género; ALONSO SALGADO y TORRADO TARRÍO (2011), pp. 567 y ss.; VÁZQUEZPORTOMEÑE SEIJAS (2013), pp. 309 y ss.; FERNÁNDEZ LÓPEZ (2015), pp. 497 y ss., en que incluso formula una propuesta detallada de protocolo de mediación penal en supuestos de violencia de género; HERNÁNDEZ HIDALGO (2017), pp. 256 y ss.

${ }^{24}$ Acerca de este tipo de políticas y su implementación en Estados Unidos, véase SHERMAN (1992), pp. 2 y ss.; HOYLE (1998), pp. 1-22; FERGUSON (2009), pp. 4 y ss.; KOHN (2010), pp. 519 y ss.; HEIM (2011), pp. 952 y ss.

${ }^{25}$ Sobre la relación existente entre las diversas corrientes del feminismo y la prohibición de la mediación, véase HOPKINS et al. (2004), pp. 297 y ss.; DALY y STUBBS (2007), pp. 150 y ss.

${ }^{26}$ Véase UMBREIT Y BOS (2000), pp. 63 y ss.; WALTERS (2015), pp. 1207 y ss.

${ }^{27}$ Entre otros, SCHIMMEL (2012), pp. 161 y ss.

${ }^{28}$ Véase KOHN (2010), pp. 541 y ss.

${ }^{29}$ Descripciones extensas pueden hallarse en MARTIN (1996), pp. 56 y ss.; KRIEGER (2002), pp. 235 y ss.; STUBBS (2002), pp. 56 y ss.; STUBBS (2007), pp. 173 y ss.; STUBBS (2010), pp. 970 y ss.; GITTLEMAN (2008), pp. 16 y ss.; GELSTHORPE (2012), pp. 398 y ss. Sobre la desigualdad de las partes, entre otros, PRANIS (2002), p. 24; DROST et al. (2015), pp. 10 y ss. En España, una exposición detallada puede encontrarse en LARRAURI PIJOAN (2007a), pp. 123 y ss.; ESQUINAS VALVERDE (2008), pp. 57 y ss.; VILLACAMPA ESTIARTE (2012), pp. 187 y ss.
} 
perdón resultan extraños a las intervenciones contemporáneas en violencia de género, que ha reaccionado contra respuestas al conflicto que busquen la reconciliación privada entre las partes, así como porque en supuestos de violencia de género no hay igualdad de armas entre las partes o porque resulta muy complejo garantizar la intervención voluntaria de ambas en el proceso- puede suponer una forma de perpetuar el ciclo que la violencia-. En segundo lugar, se hace referencia al grupo de inconvenientes relacionados con la imposibilidad de aplicar la justicia restaurativa a casos de violencia de género partiendo de argumentos feministas. Los mismos se fundamentan en lo antitético de este proceder con la idea defendida desde el feminismo de segunda ola de que la violencia de género ha pasado de ser una cuestión ventilada en la intimidad domiciliaria a constituir un hecho con relevancia penal, convirtiéndose con ello en materia de Derecho público. Se añade a esto que el retorno de la resolución de dichas cuestiones a la esfera de lo privado supondría la pérdida del simbolismo alcanzado al conseguir que frente a ellas se articulara la respuesta institucional, ofreciendo un mensaje de laxitud y trivializando estas manifestaciones de la violencia. En tercer lugar, se incluyen los argumentos contra el empleo de mecanismos de justicia restaurativa en casos de violencia de género basados en la inefectividad de esta forma de justicia como respuesta a este tipo de violencia. Se entiende que la misma no solo no es capaz de acabar con estas situaciones violentas, sino que ni siquiera basta para garantizar la seguridad de las víctimas o su bienestar psicológico. En último término, se incluyen argumentos aducidos desde ópticas diversas al feminismo oficialista relativos a que la justicia restaurativa pueda resultar injusta para los propios ofensores, por entender que estos pueden igualmente verse forzados a intervenir en este tipo de procesos.

\section{Ventajas que se atribuyen al recurso a la justicia restaurativa en casos de violencia de género}

La prohibición legal en España constituye al tiempo una posición inflexible que desoye que no son pocos precisamente los aspectos positivos que se predican de la aplicación de mecanismos de justicia restaurativa a supuestos de violencia de género. Desde las propias filas del feminismo, opciones alejadas del feminismo radical, integradas en lo que se conoce como feminismo de tercera ola, ${ }^{30}$ destacan la posibilidad de que la aplicación de este tipo de mecanismos pueda generar rendimientos positivos, sobre todo

\footnotetext{
${ }^{30}$ Esta facción del pensamiento académico feminista, en general, y de la teoría legal feminista, en particular, constituye un conjunto de posicionamientos diversos, conformados por el feminismo postmoderno y postcolonial, todavía en evolución, que surgen como respuesta al esencialismo de género centrado en la mujer blanca occidental de clase media propio del feminismo de segunda ola. Rompen con la suficiencia de la condición de ser mujer para explicar la opresión o las relaciones de poder de los hombres sobre las mujeres, con la idea misma de mujer, con la de la diferencia binaria de género y con la del patriarcado mismo. Para estas feministas el concepto de mujer deja de ser el centro al que dirigir todas las referencias; en lugar de hablar de mujeres, emplean conceptos más comprensivos, como "sujeto excéntrico", "cyborg", "nómadas" o "figuraciones". Cuestionan la heterosexualidad como base y la propia diferencia entre género culturalmente creado sobre la base del sexo, determinado biológicamente, asumiendo que tanto género como sexo se construyen culturalmente y que no son necesariamente binómicos. En lugar de al patriarcado, sitúan en el centro del sistema a la interseccionalidad, según la que los procesos de subordinación que sufren los individuos en la sociedad moderna no se basan solamente en el sistema binómico sexo-género, sino también en variables como la raza o la clase social. La denominación de esta corriente del pensamiento feminista se ha atribuido a WALKER (1992), pp. 39-41. Entre sus obras más representativas se cuentan: BRAIDOTTI (2000), pp. 1- 254; BUTLER (2007), pp. 1310; CRENSHAW (1989), pp. 139-167; CRENSHAW (1991), pp. 1241-1299; DE LAURETIS (2000), pp. 1-173; HARAWAY (1995), pp. 1-439; MOHANTY (2008a), pp. 117-164; MOHANTY (2008b), pp. 407-464; SPYVAK (2010), pp. 1-416.
} 
en los casos en que los programas atiendan a la particularidad de estos supuestos de violencia y se diseñen teniendo en cuenta sus singularidades ${ }^{31}$. De un lado, aspectos como que los procesos de justicia restaurativa permiten un encuentro dialogado entre las víctimas, los ofensores y los facilitadores de este tipo de programas son destacados en este sector, que apela a cómo mediante estos se incrementan las posibilidades de condena de la violencia en formas que resultan significativas y consecuentes tanto para los infractores como para las víctimas, permitiendo a estas explicar sus propias historias sobre la violencia sufrida ${ }^{32}$. Dan con ello además satisfacción a una de las demandas más habituales de este tipo de víctimas cuando pasan por el sistema de justicia penal, que es precisamente la de ser escuchadas ${ }^{33}$. A ello se añade que estos sistemas confieren a las víctimas el protagonismo en la resolución del conflicto que la justicia retributiva, tan solo preocupada en utilizarlas como fuentes de prueba, les niega. Se incrementa así su nivel de satisfacción al valorar el tratamiento recibido en este tipo de procesos ${ }^{34}$.

De otro lado, se valora positivamente que los procesos de justicia restaurativa dan respuesta a las víctimas que no persiguen la acusación formal del ofensor; a aquellas que acuden a la policía no para que se procese formalmente al mismo, ni siquiera con la intención de dar por concluida la convivencia o la relación con este, sino para obtener protección inmediata. ${ }^{35}$

Junto a las ventajas que la implementación de este tipo de mecanismos tiene para con las víctimas, se ha indicado que favorecen en mayor medida que los procesos basados en un paradigma retributivo de la justicia la admisión de responsabilidad de los hechos cometidos por parte del ofensor. Este efecto se muestra particularmente relevante en los supuestos en que se cometen delitos contra la libertad sexual, ${ }^{36}$ donde la acusación se halla particularmente dificultada por la general ausencia de testigos. No obstante, esta ventaja podría perfectamente también predicarse de los supuestos de violencia de género que no implican violencia sexual, ${ }^{37}$ habida cuenta del elevado recurso evidenciado por parte de las víctimas en España a la dispensa del deber de declarar contra el cónyuge contemplado en el art. 416 de la Ley de Enjuiciamiento Criminal.

Finalmente, sin atender a los beneficios del proceso para la víctima o el ofensor singularmente considerados, sino respecto de todos los que intervienen en el mismo, se ha destacado en favor de la implementación de este tipo de mecanismos en supuestos de violencia de género que otorga atención a visiones legas, más que técnicas o legales del delito. Con ello se favorece una comprensión más integral del mismo y, por tanto, menos apegada a la relevancia generalmente penal de la conducta, pese a que debe andarse con cuidado acerca de que sea precisamente personal lego quien se encargue de conducir estos procesos restaurativos.

\footnotetext{
${ }^{31}$ Véase MORRIS y GELSTHORPE (2000), pp. 412 y ss.; PENNELL y BURFORD (2002), pp. 121 y ss.; SOKOLOFF Y DUPONT (2005), pp. 55 y ss.; STUBBS (2007), pp. 180 y ss.; ARNOLD y AKE (2013), pp. 572 y ss. Para una exposición detallada en España de los argumentos favorables a la implementación de la justicia restaurativa en supuestos de violencia de género, puede consultarse LARRAURI PIJOAN (2007a), pp. 127 y ss.; ESQUINAS VALVERDE (2008), pp. 127 y ss.

${ }^{32}$ Ver CURTIS-FAWLEY y DALY (2005), p. 609.

${ }^{33}$ Confrontar STUBBS (2002), p. 51 ; DROST et al. (2015), p. 13.

${ }^{34}$ Véase BURKEMPER y BALSAM (2007), p. 126.

${ }^{35}$ HOYLE (1998), pp. 186 y ss.; HOYLE y SANDERS (2000), p. 22; CURTIS-FAWLEY y DALY (2005), p. 609.

${ }^{36}$ Ver CURTIS-FAWLEY y DALY (2005), p. 609.

${ }^{37}$ PELIKAN (2010), pp. 49 y ss. ; DROST et al. (2015), p. 13.
} 


\section{Experiencias y evaluaciones positivas del empleo de procesos de justicia restaurativa en casos de violencia de género}

Pese a las dificultades que parece entrañar el empleo de mecanismos de justicia restaurativa en supuestos de violencia de género, de lo dicho puede colegirse que las ventajas que a priori pueden derivarse de tal implantación superan los inconvenientes. Así parece inferirse de las diversas comprobaciones efectuadas respecto del grado de satisfacción de las víctimas ante este tipo de procesos, que en general arrojan un resultado positivo. Las víctimas tienden a mostrar un mayor grado de satisfacción por su intervención en tales procesos basado en la mayor participación que los mismos les brindan en relación con la restitución financiera o material finalmente obtenida del ofensor $^{38}$. En un meta análisis de justicia restaurativa efectuado en 2001 se concluyó que la participación en programas de justicia restaurativa incrementa con carácter general tanto el grado de satisfacción de las víctimas como de los ofensores ${ }^{39}$. En general, la literatura informa acerca de que las víctimas valoran que se les dé la oportunidad de hablar sobre su proceso de victimización, ${ }^{40}$ además de reducirse sentimientos como la ansiedad o el miedo y favorecer la recuperación de la autoestima $^{41}$.

Menos habituales resultan los análisis focalizados en el empleo de mecanismos de justicia restaurativa en supuestos de violencia de género. Sin embargo, las comprobaciones acerca del grado de satisfacción de las víctimas que han pasado por diversos programas de justicia restaurativa diseñados para casos de violencia de género entre íntimos arrojan invariablemente resultados positivos. Así ha sucedido con programas de conferencias de grupos de familia como el implementado por Joan Pennell y Gale Burford en Newfounland y Labrador (Canadá), ${ }^{42}$ o con programas basados en los círculos de paz de la comunidad Navajo con mujeres hispanas maltratadas en Nogales (Arizona, USA) implementados por Linda Mills y Mary Hellen MALEY. ${ }^{43}$ También ha sucedido así con los de mediación víctima ofensor más generalizados en Europa como el monitorizado por Christa PELIKAN de casos gestionados por la Oficina de Compensación Extrajudicial en Austria, uno de los países europeos con más tradición en la aplicación de mecanismos de justicia restaurativa en supuestos de violencia de género. ${ }^{44}$ Más recientemente, circunscribiendo el espectro a experiencias de justicia restaurativa aplicadas en seis países europeos -Austria, Finlandia, Dinamarca, Holanda, Grecia y Gran Bretaña-, un estudio cualitativo que ha evaluado los programas de mediación víctima-ofensor aplicados en supuestos de violencia familiar producida por la pareja, concluye que tanto las víctimas como los ofensores se consideran en general satisfechos con los resultados de estos programas. El referido análisis concluye que la condición que más garantiza la satisfacción de las

\footnotetext{
${ }^{38}$ SHERMAN y STRANG (2007), p. 64.

${ }^{39}$ Véase LATIMER et al. (2005), pp. 127-144.

${ }^{40}$ Véase UMBREIT et al. (2004), pp. 279 y ss.

${ }^{41}$ WEMMERS y CYR (2005), pp. 527 y ss; SHAPLAND et al. (2007), pp. 36-48; ANGEL et al. (2014), pp. 291 y ss.

${ }^{42}$ Acerca de las características y los resultados de dicho programa, consúltese BURFORD y PENNELL (1998), pp. 1-250; PENNELL y BURFORD (2000), pp. 131 y ss.; PENNELL y BURFORD (2002), pp. 109 y ss.

${ }^{43}$ MILLS et al. (2009), pp. 145 y ss.

${ }^{44}$ PELIKAN (2000), pp. 1 y ss.
} 
víctimas con tales programas consiste en la posibilidad de hablar de la violencia sufrida y de condenarla en un contexto seguro ${ }^{45}$.

En España no contamos con evaluaciones sobre el funcionamiento de programas de justicia restaurativa implementados en contextos de violencia de género precisamente porque tal posibilidad se halla vetada normativamente por obra de la LO 1/2004. Sin embargo, debe destacarse como los profesionales del sistema de justicia penal que han estado en contacto con la aplicación de programas de justicia restaurativa a esta realidad criminal se muestran generalmente favorables a su admisibilidad normativa y aplicativa. Así se deduce de los resultados arrojados por diversas investigaciones empíricas efectuadas en España con profesionales forenses y del ámbito asistencial de las que seguidamente se da sucinta cuenta.

En el caso de Cataluña, en el estudio que se efectuó para la elaboración del libro blanco sobre mediación en los casos en que se había aplicado mediación en el programa de mediación y reparación, ${ }^{46}$ aunque se alude al límite legal a la mediación en supuestos de violencia de género, y se indica cómo en la justicia de adultos, a diferencia de la de menores, la mediación penal tiene carácter testimonial, se reconoce que se había mediado en 72 casos de violencia familiar. ${ }^{47}$ Los coordinadores de los programas de mediación entrevistados para la elaboración de este estudio manifestaron que los conflictos asociados a la violencia intrafamiliar eran especialmente graves y que se habían incrementado, lo mismo que los derivados de la situación de crisis económica y los propios de la convivencia vecinal. Generalmente los supuestos de violencia familiar se consideran difíciles de abordar porque habitualmente constituyen conflictos complejos a los que precede un proceso de deterioro de la relación que puede haber durado años ${ }^{48}$. Ello hace que los mediadores a veces muestren su desaliento, en el sentido de reconocer su incapacidad para arreglar el conflicto de tantos años en un proceso de mediación. Sin embargo, lejos de considerar que tal circunstancia debería conducir a que en estos casos no se previera la posibilidad de mediar, lo que se demanda es que sean conducidos por equipos especializados. ${ }^{49}$ Junto a ello, la opinión mayoritaria de los jueces y magistrados que habían tenido casos derivados a programas de mediación converge en que la prohibición contenida en la LO 1/2004 provoca claros desajustes. Según estos, en ocasiones los conflictos tratados por los órganos jurisdiccionales conforme a esta política punitivista no solo no se resuelven satisfactoriamente, sino que incluso pueden verse agravados, añadiéndose que para muchos de estos operadores la mediación podría ser una vía de resolución de conflictos en el ámbito de la violencia doméstica ${ }^{50}$.

En relación con el programa de mediación penal en adultos del País Vasco, ya se ha indicado como se ha admitido formalmente incluso después de 2004 mediación en casos que pueden considerarse de violencia de género. Respecto de este instrumento restaurativo en términos generales, en la evaluación del programa de mediación efectuada en 2009 los jueces mostraron una actitud más positiva que los fiscales

\footnotetext{
${ }^{45}$ LÜNNEMANN Y WOLTHUIS (2015), pp. 11 y ss.

${ }^{46}$ Los resultados del estudio pueden verse en MARTÍN et al. (2010), pp. 604 y ss.

${ }^{47}$ Véase MARTÍN et al. (2010), p. 609, del total de casos de mediación de adultos, que se elevó a 490.

${ }^{48}$ Véase MARTIN et al. (2010), p. 614.

${ }^{49}$ MARTÍN et al. (2010), p. 616.

${ }^{50}$ Ver MARTÍN et al. (2010), p. 619.
} 
respecto de su empleo. ${ }^{51}$ En referencia a la mediación en casos de violencia de género en concreto, solo dos de los profesionales encuestados (menos del 10\%) se mostraron contrarios a su viabilidad en tales casos, y más que oposición se observó que de lo que se trataba era de resignación frente a la prohibición legal. El 70\% de los entrevistados estimó que la misma era posible salvaguardando la libertad y la igualdad de las partes y el $20 \%$ restante la admitían solo en casos en que la violencia no sea habitual ${ }^{52}$.

Para concluir con las opiniones profesionales, una visión igualmente favorable a la adopción de tal tipo de programas se observa en los estudios cualitativos con profesionales coordinados por el CGPJ, el primero llevado a cabo con 30 profesionales 9 jueces y 21 fiscales- en $2009,{ }^{53}$ y el segundo, en 2015 , una vez aprobada la Ley $4 / 2015$, para preguntar a los jueces -concretamente a una muestra de 48 profesionalesqué contenidos debería tener la formación que recibiesen en un futuro curso formativo sobre mediación ${ }^{54}$. En ambos casos, sin embargo, la visión esperanzada respecto de la activación de este tipo de programas contrastaba con la valoración negativa que les merecía la ausencia de regulación legal exhaustiva de tal posibilidad, lo que generaba inseguridad entre los profesionales y disparidad de criterios de actuación entre unos órganos judiciales y otros. Si bien en el segundo de los informes los profesionales forenses pusieron el acento en la necesidad de formación de los profesionales, en el primero de ellos, tanto jueces (7 de los 9 entrevistados) como fiscales (90\% de los entrevistados) se mostraron mayoritariamente partidarios de aceptar el recurso a la mediación en casos de violencia de género.

La valoración que las víctimas efectúan de la implementación de mecanismos de justicia restaurativa en supuestos de violencia de género en España no ha podido ser conocida precisamente porque formalmente apenas pueden existir programas de este tipo para estos casos. Con todo, la primera evaluación con usuarios de estos programas fue llevada a cabo en el País Vasco durante la primera década del siglo XXI. En 2008 se evaluó el programa de Barakaldo, dado el rápido incremento de derivaciones, ${ }^{55}$ acometiéndose posteriormente una evaluación de los cuatro servicios de mediación existentes en el País Vasco en que se entrevistó a una muestra de 598 personas, de las que un $42 \%$ eran víctimas, un $40 \%$ infractores y un $18 \%$ con doble rol (víctima e infractor ${ }^{56}$. Los resultados de la evaluación fueron en general favorables a la mediación, puesto que un $76 \%$ de los participantes afirmaron que recomendarían la participación en una mediación penal y un porcentaje similar consideró que se había alcanzado un resultado justo, afirmando un 58\% que se habían sentido reparados y proclamando que repetirían un procedimiento de mediación, preferentemente directo ${ }^{57}$.

Además, la prohibición legal de la mediación en casos de violencia de género no quita que de la evaluación efectuada del programa catalán de mediación penal en adultos realizada con víctimas derivadas al mismo entre 2011 y 2012 no puedan extraerse algunos resultados sobre la satisfacción de las víctimas que resultarían trasladables a los supuestos de violencia de género. Esto porque algunos de los casos mediados podrían

\footnotetext{
${ }^{51}$ VARONA MARTÍNEZ (2009), pp. 223-230.

52 VARONA MARTÍNEZ (2009), pp. 223-230.

53 SÁEZ (dir.) (2010), pp. 28-36.

${ }^{54}$ BUTTS Y GUILARTE GUTIÉRREZ (2015), pp. 12-15.

${ }^{55}$ VARONA MARTÍNEZ (2008), pp. 1-114.

${ }^{56}$ VARONA MARTÍNEZ (2009), pp. 66 y ss.

${ }^{57}$ VARONA MARTÍNEZ (2009), pp. 95-100.
} 
efectivamente haberse producido en tales contextos violentos, si bien sin resultar de la competencia de los Juzgados de Violencia sobre la Mujer. Los resultados de la investigación - consistente en cuestionarios efectuados a 121 víctimas, de las que 90 fueron además entrevistadas telefónicamente - ${ }^{58}$ ponen de manifiesto como los procesos de mediación contribuyen a la recuperación emocional de las víctimas, además de proveerlas de un mejor sentido de la justicia que el sistema de justicia penal, tanto en términos de dimensión procedimental cuanto terapéutica de la justicia. ${ }^{59}$ Sin embargo, aun constatando los efectos emocionales positivos que los procesos de mediación tienen en las víctimas, la investigación concluye como en los conflictos que implican miembros de una misma familia y parejas, pese a la inicial disposición de las víctimas a tomar parte en esos procesos, se confirma la dificultad de alcanzar los objetivos del programa, sobre todo porque los ofensores tendían a ser más reacios a asumir su responsabilidad y disculparse. Sobre dicha base, los investigadores muestran sus dudas acerca de que la mediación víctima-ofensor sea eficaz para tratar efectivamente los problemas de largo recorrido en relaciones cercanas, lo que interpretan como una limitación de este instrumento de justicia restaurativa. De ahí que se decanten por el empleo de conferencias de grupos de familia, que a su juicio constituye una herramienta restaurativa más completa y apta para resolver situaciones más complejas, ${ }^{60}$ como las producidas en estos supuestos.

Pero es que además tampoco se ha confirmado que el empleo de mecanismos de justicia retributiva como los articulados por la LO 1/2004 haya servido hasta el momento ni para reducir las cifras de violencia de género en España ni para afianzar la confianza de las víctimas en el funcionamiento del sistema. Pese a que esta norma ha sido una de las más evaluadas de cuantas se han aprobado en el ámbito jurídico-penal, los análisis existentes se limitan a operar con datos sobre criminalidad oficial, policiales y judiciales, pero no sobre datos relativos a victimización. Se ha objetivado un descenso paulatino de las denuncias por violencia de género desde 2008, con ligero repunte en 2014, pero esto, más allá de sugerir la posibilidad de que la LO 1/2004 no esté siendo tan eficiente como inicialmente apareció para hacer aflorar este tipo de violencia, no nos ofrece información acerca del número de víctimas de este fenómeno. Es imposible acudir con dicho objetivo a las encuestas de victimización realizadas en España sobre violencia de género, puesto que aunque se han efectuado cinco encuestas de amplio espectro con dicho objeto - tres de ellas coordinadas por el Instituto de la Mujer en 1999, 2002 y 2006, y las dos últimas, en 2011 y 2015, realizadas bajo los auspicios del Observatorio Estatal de Violencia sobre la Mujer-, los datos que arrojan no permiten su comparación longitudinal, al haberse empleado instrumentos diversos que conducen a la obtención de resultados no comparables. Puede servir entonces como indicador de la eficacia de esta norma el número de muertes violentas de mujeres a manos de sus parejas o exparejas, que es fácilmente constatable que no han disminuido con la aprobación de la ley. Así, atendiendo a los últimos datos publicados por la Secretaría de Estado de Igualdad, ${ }^{61}$ puede confirmarse que aunque se pasó de los 72 feminicidios de 2004 a los 57 de 2005 como efecto inmediato de la aprobación de la LO 1/2004, el número anual de muertes de mujeres a manos de sus parejas o exparejas ha tenido después ligeras oscilaciones no atribuibles a esta norma.

\footnotetext{
${ }^{58}$ Sobre la metodología de la investigación, véase TAMARIT y LUQUE (2016), pp. 72 y ss.

${ }^{59}$ Confróntese TAMARIT y LUQUE (2016), pp. 74 y ss.

${ }^{60}$ Véase TAMARIT y LUQUE (2016), p. 82.

${ }^{61}$ Véase SECRETARÍA DE ESTADO DE IGUALDAD-DELEGACIÓN DEL GOBIERNO PARA LA VIOLENCIA DE GÉNERO (2018), p. 9.
} 
Junto a esto, en relación con el recurso de las víctimas a un sistema de justicia penal retributivo como el presente para poner fin a la situación, la última macroencuesta sobre violencia de género, informa que, si bien el $75 \%$ de las mujeres que han sufrido violencia física o psicológica a manos de su pareja o expareja o han creído estar en riesgo de padecerla han explicado lo sucedido a alguien de su entorno, y el $45 \%$ de ellas ha acudido a algún servicio médico, legal o social, sólo el $28,6 \%$ han acudido a la policía. ${ }^{62}$ A lo que se añade que, cuando se pregunta a las mujeres por qué tipo de ayudas preferirían recibir, indican en un $70 \%$ de los casos que apoyo psicológico, relegando al 34\% la demanda de apoyo legal y al 14\% el empleo de instrumentos electrónicos de monitorización y contención del maltratador ${ }^{63}$. Se deduce de estos datos, pues, que las víctimas valoran y priorizan el acceso a recursos asistenciales en los que sustentar su proceso de recuperación frente al recurso a un sistema de justicia penal centrado en la retribución.

En definitiva, como ya en su momento indicara SHERMAN, incluso aunque existen pocas evidencias empíricas de que el empleo de la justicia restaurativa reduce efectivamente la violencia en la pareja, tampoco las hay de que el empleo de formas de justicia tradicional haya sido capaz de reducir los porcentajes de violencia, incluida también la doméstica. ${ }^{64}$ En tal contexto, no resulta indicado afirmar que no debe experimentarse con el empleo de mecanismos de justicia restaurativa, cuando no existe evidencia de que experimentar en este campo sea más peligroso que no experimentar en él.

Más bien podría decirse que quedarnos como estamos en España, esto es, con la taxativa prohibición del empleo de la mediación en los supuestos de violencia de género, va contra la evidencia hasta ahora deducida de las monitorizaciones efectuadas respecto de programas de conferencias de grupos de familia, círculos de paz o mediación en supuestos de violencia de género en aquellos países en que han podido implementarse tales programas y efectuarse las correspondientes evaluaciones.

\section{Situación normativa internacional y en Derecho comparado}

En relación con lo hasta ahora indicado, lo que todavía resultaría más incomprensible es que con el mantenimiento de la referida prohibición legal España se situaría en una inusitada posición contraria a esta posibilidad que no resulta a estas alturas ya ni mantenida por países de nuestro entorno jurídico ni sustentada en normativa internacional.

De hecho, internacionalmente el empleo de mecanismos de justicia restaurativa en supuestos de violencia de género no se prohíbe. En concreto, no se refiere a los supuestos de mediación en casos de violencia de género ni doméstica la Directiva 2012/29/UE que, sin embargo, sí obliga a los Estados miembros a tomar medidas que aseguren que las víctimas que escojan participar en procesos de justicia restaurativa tengan acceso a servicios que la provean seguros y competentes. Sí se refiere específicamente a ella el Convenio de Estambul de 2011, que establece en su art. 48 la

\footnotetext{
${ }^{62}$ Confróntese DELEGACIÓN DEL GOBIERNO PARA LA VIOLENCIA DE GÉNERO (2015), pp. 17 20 .

${ }^{63}$ DELEGACIÓN DEL GOBIERNO PARA LA VIOLENCIA DE GÉNERO (2015), p.37.

${ }^{64}$ Véase SHERMAN (2000), p. 287.
} 
prohibición de los modos alternativos de resolución de conflictos en las formas de violencia incluidas en el Convenio solo cuando estos se imponen obligatoriamente. ${ }^{65}$ Esto es, partiendo de la voluntariedad del recurso a mecanismos de justicia restaurativa, el Convenio se limita a prohibir que estas formas de resolución de conflictos se impongan contra la voluntad de la víctima. Con la finalidad de evitar que siga perteneciendo al ámbito de lo privado lo que lo fuera antes de que comenzaran a perseguirse penalmente las manifestaciones de la violencia de género en el ámbito de la familia, los redactores del Convenio exigen que los Estados Parte provean a las víctimas la posibilidad de acudir a un proceso adversarial conducido ante un juez imparcial, sin ser forzadas a acudir a mecanismos alternativos de resolución que pueden incrementar sus sentimientos de vergüenza, indefensión o vulnerabilidad mientras el ofensor exhibe su poder y dominación. ${ }^{66}$ Al margen de los supuestos de intervención obligatoria en tales mecanismos de justicia alternativa, el Convenio no prohíbe su empleo cuando la intervención sea voluntaria para las partes.

Ante dicha ausencia de prohibición normativa internacional, diversos Estados europeos que han admitido el empleo de procesos de justicia restaurativa en supuestos de violencia de género han implementado programas de mediación o conferencias de grupos de familia específicamente diseñados para tales supuestos. ${ }^{67}$ Así ha sucedido con los seis países europeos antes indicados en que se había evaluado el funcionamiento de tales programas, desde los más pioneros y experimentados en este tipo de prácticas, como especialmente Austria, pero también Finlandia, hasta los que han implementado más tarde mecanismos de este tipo, como Gran Bretaña.

Algunos de estos países contemplan normativamente desde hace años la introducción de mecanismos de justicia restaurativa. El primer país en admitir legalmente el recurso a tales instrumentos incluyendo la violencia de género en el ámbito de la pareja fue Austria en 2000, con la correspondiente modificación de su Código Procesal Penal. En segundo término, lo hizo Finlandia, donde ya en 2006 entró en vigor una ley específica de mediación en casos penales y algunos casos civiles. En Grecia, la mediación en casos de violencia de género en la pareja fue introducida en 2007 como resultado de la adaptación de la legislación interna a las decisiones de la Unión Europea. En la otra mitad de los países, sin embargo, la normativa en materia de justicia restaurativa se aprobó más recientemente. En Gran Bretaña, hasta la aprobación de la Crime and Courts Act de 2013, que la introduce en la justicia penal de adultos facultando a los tribunales a derivar los casos cuando las partes estén de acuerdo, la justicia restaurativa en este campo se había venido implementando sobre bases no legales. En Holanda, el Código de Procedimiento Penal permite acudir a la mediación cuando indica que la oficina del Ministerio Fiscal debe proveer lo necesario para que la policía informe lo antes posible tanto a víctima como a ofensor de la posibilidad de acudir a la mediación.

\footnotetext{
${ }^{65}$ Dispone el art. 48 Convenio Estambul "Prohibición de modos alternativos obligatorios de resolución de conflictos o imposición de condenas. 1. Las Partes adoptarán las medidas legislativas o de otro tipo necesarias para prohibir los modos alternativos obligatorios de resolución de conflictos, incluidas la mediación y la conciliación, en lo que respecta a todas las formas de violencia incluidas en el ámbito de aplicación del presente Convenio. 2. Las Partes adoptarán las medidas legislativas o de otro tipo necesarias para que, en el caso de que se condene al pago de una multa, se tenga debidamente en cuenta la capacidad del autor del delito para hacer frente a las obligaciones económicas que tenga contraídas con la víctima".

${ }^{66}$ Acerca de las razones de inclusión de dicha prohibición, puede consultarse, COUNCIL OF EUROPE (2011), p. 42.

${ }^{67} \mathrm{Al}$ respecto, pueden verse los descritos en DROST et al. (2015), pp. 21 y ss.
} 
En Dinamarca, la regulación resulta mucho más extensa, puesto que en 2010 se aprobó una ley que regulaba la mediación complementaria a los procedimientos penales ante los tribunales. ${ }^{68}$

\section{Conclusiones: algunas proposiciones político-criminales relativas a la deseable inclusión de mecanismos de justicia restaurativa en supuestos de violencia de género en España}

En conclusión, tanto con base en la evidencia empírica derivada de la monitorización de programas de justicia en general y de los diseñados para los casos de violencia de género en particular, como porque en normativa internacional que vincula al Estado español no se establece prohibición en dicho sentido, debería suprimirse el actual art. 87 ter 5 LOPJ que fuera introducido por la LO 1/2004 y que prohíbe la práctica de la mediación en supuestos de violencia de género. Suprimido dicho precepto de nuestro ordenamiento jurídico, nada impediría aplicar este tipo de instrumentos a los casos de violencia de género en el marco normativo que brindan los arts. 15 Ley 4/2015 y 37 RD 1109/2015, si bien resultaría deseable también la supresión de la referencia a las prohibiciones de mediación que el primero contiene.

Sin embargo, debe subrayarse que dichos preceptos tan solo indican los requisitos que tienen que cumplirse para que las causas puedan ser derivadas a mediación, así como quién puede efectuar la propuesta de derivación al órgano judicial —las oficinas de asistencia a las víctimas-. Nada dicen del momento procesal en que puede procederse a la mediación - en instrucción, en fase de juicio oral o ya en ejecución de sentencia o en cualquier de ellos-, o del procedimiento mediante el que puede procederse a la aplicación de un mecanismo alternativo de resolución de conflictos. Guardan también silencio acerca de los instrumentos a que puede acudirse - si cabe solo mediación víctima ofensor, o se aceptan también conferencias de grupos de familia, círculos de paz o incluso paneles de impacto a víctimas-, de los efectos que produce el acuerdo al que las partes hayan arribado en el procedimiento penal, o de cómo de articula el control del cumplimiento de lo acordado. Ni siquiera se establece cuáles son las características que debe tener el mediador o facilitador, esto es, si debe ser un profesional o puede también ser un lego. E incluso más, no queda claro si la implementación de mecanismos de justicia restaurativa se prevé solo como complementaria al proceso penal, esto es, en el marco del mismo, en lo que reina claro acuerdo doctrinal, o bien incluso cabría la aplicación de mecanismos de resolución del conflicto completamente alternativos al procedimiento penal —opción que platea bastantes más problemas de encaje con el sistema de justicia penal- , lo que podría llegar a entenderse como posibilidad sugerida por el legislador español al referirse en el art. 37 RD 1109/2015 a los servicios de mediación extrajudicial que ni siquiera aparecen caracterizados normativamente.

A la vista de los vacíos regulativos enunciados parece, pues, evidente que el legislador español no ha tomado seriamente en consideración que la justicia restaurativa puede constituir una magnífica herramienta que atempere los indeseados efectos producidos por la justicia retributiva. Tanto es así que carga a las oficinas de asistencia a las víctimas, organismos públicos claramente insuficientes, con la competencia de proponer al órgano judicial la derivación de los casos a mediación, cuando en la mayor parte de

\footnotetext{
${ }^{68}$ Acerca de estas regulaciones, puede consultarse DROST et al. (2015), p. 18.
} 
países europeos esa función es llevada a cabo por el Ministerio Fiscal, que deriva directamente o propone la derivación.

En definitiva, resulta evidente que la real implementación de la justicia restaurativa en la justicia penal de adultos requiere de una voluntad política que no parece concurrir en este momento en la arena española y que para activarse debería, en primer lugar, plasmarse en una adecuada regulación legal detallada de la justicia restaurativa. Dicha reglamentación debería ser, cuanto menos, del tipo de la que en su momento incluyera el Anteproyecto de Ley de Enjuiciamiento Criminal de 2011, para la que bien podrían resultar de utilidad algunos de las disposiciones contenidas en el actual protocolo de derivación a mediación del CGPJ. Hecho esto, debería tenerse en cuenta que los supuestos de violencia de género plantean una serie de especificidades que podrían hallarse contempladas mediante una referencia sucinta en la Ley rituaria y que, con carácter más detallado, podrían regularse en un eventual protocolo de mediación aplicable a supuestos específicos ${ }^{69}$.

Al respecto, quizá convendría aclarar que cualquier supuesto de violencia de género puede ser objeto de mediación, no solamente aquellos que consistan en el uso ocasional de la violencia. Incluso los casos de empleo de violencia habitual podrían ser derivados a un mecanismo alternativo de resolución de conflictos siempre que pudiera acabarse garantizando el equilibrio de fuerzas de las partes en el proceso, lo que debería decidirse caso por caso. Admitida la posibilidad en abstracto, se debe atender a que uno de los temores manifestados en punto a la operatividad de los procesos de mediación en tales supuestos es el posible desequilibrio de poder entre las partes. Garantizarlo para asegurar que la decisión de acudir a la mediación ha sido efectivamente libre y voluntaria y que ambas partes, pero especialmente la mujer, están en condiciones de acudir a la misma en un modo en que puedan mantener una mínima asertividad, debe constituir un objetivo prioritario.

De ahí que sería necesario que antes de la derivación del caso a la mediación se previese la realización de algún tipo de pericia — por ejemplo, un informe psico-social — que ayudase al operador jurídico concreto a decidir acerca de la conveniencia o no de la derivación del caso a tal proceso restaurativo. El contenido del informe podría revelar si, cuanto menos apriorísticamente, la mujer o la parte más débil en la mediación - el anciano, o el niño, por ejemplo, en casos de violencia familiar no necesariamente de género- están en condiciones de encarar adecuadamente un proceso restaurativo. Se evitaría con ello impeler a un proceso de negociación a personas que no están preparadas para él, que pueden verse eventualmente "presionadas" a aceptar unas disculpas no sinceras, y que pueden acabar experimentando el proceso supuestamente restaurativo como un episodio más en su historia de subyugación.

El proceso de mediación propiamente dicho también debería atender a las especificidades que supone la intervención en supuestos de violencia de género. En primer lugar, podría suceder que la víctima no se hallase psicológicamente preparada para acudir a un proceso de mediación en determinado momento, pero que el trabajo terapéutico con ella pudiese capacitarla para dicha intervención a posteriori; en tal sentido, los plazos de derivación al mismo deberían ser lo suficientemente flexibles para que dicha derivación pudiese producirse con carácter posterior. De la misma forma,

\footnotetext{
${ }^{69}$ Las que aquí se listan fueron ya expuestas en VILLACAMPA ESTIARTE (2012), pp. 210 y ss.
} 
debería poder garantizarse la reversión de la derivación al proceso restaurativo si, una vez producida esta, se observa que la víctima no se haya suficientemente empoderada, contra lo que inicialmente hubiera podido valorarse. También en este caso, la emisión de un informe técnico debería constituir la base sobre la cual redirigir el caso a la justicia penal tradicional sin que, por supuesto, nada de lo actuado en el proceso restaurativo ya iniciado pudiese trascender al correspondiente proceso penal.

Respecto del instrumento de justicia restaurativa concreto empleado, pese a que ha habido quien ha sugerido que en tales casos puede resultar más adecuado el recurso a conferencias de grupos de familia, ${ }^{70}$ lo cierto es que tanto el art. 15 Ley 4/1015 como el art. 37 RD 1109/2015 se refieren explícitamente solo a la mediación. La misma, además de ser el mecanismo de justicia restaurativa más próximo a la cultura occidental, es el más habitualmente aplicado a supuestos de violencia de género en la pareja en los países de nuestro entorno jurídico, ${ }^{71}$ por lo que únicamente se efectuarán algunas puntualizaciones sobre las cuestiones a considerar en los casos de violencia de género cuando se derivan a mediación.

En tal sentido, entre los correctivos a aplicar a estos supuestos, nada impediría que en el proceso de mediación pudiese discriminarse en positivo a favor de la parte más débil, pues ello no tendría por qué comprometer la imparcialidad o la neutralidad del proceso, antes al contrario, contribuyendo a garantizarla cuando los mecanismos de compensación empleados sean los adecuados. A este respecto, el trabajo del facilitador con las partes, pero especialmente con la que tiene una posición más débil, podría resultar determinante. Eso requiere, por supuesto, de la especialización de los equipos de mediación, dado que la mediación practicada por personas escasamente especializadas, aunque voluntariosas, puede poner a las mujeres en situaciones de riesgo elevado, al no saber reconocer las señales de peligro hacia la seguridad de las mujeres y ni siquiera ser capaces de identificar manipulaciones del proceso que pueden estarse llevando a cabo por el maltratador durante el desarrollo de las sesiones ${ }^{72}$. Esto último es especialmente relevante para casos como los que nos ocupan, en que cabe que durante el proceso de mediación se aborden cuestiones relacionadas con la posible contribución de la víctima al desencadenamiento de la conducta violenta; esto es, que aflore en el proceso lo que desde la victimología se ha identificado con la victimo-precipitación y que, en estrictos términos dogmático-penales, ha dado lugar a lo que se conoce como consideraciones victimo-dogmáticas. La admisibilidad de que tales cuestiones puedan ser abordadas en un procedimiento restaurativo requiere, pues, además de una víctima que haya superado el trauma y que pueda considerarse ya superviviente, de facilitadores formados que sean capaces de evitar que discursos culpabilizadores de la víctima que sean fruto fundamentalmente de la manipulación y de las ansias de autoexculpación del maltratador que no son consecuencia de lo realmente sucedido, obtengan una indebida relevancia en el proceso.

Además de la necesaria formación de los mediadores, también otras características de los mismos pueden resultar relevantes, así el sexo de los facilitadores - algunos países prefieren emplear equipos mixtos con facilitadores hombre y mujer para los casos de violencia de género, mientras en otros es la víctima a quien se le confiere la facultad de

\footnotetext{
${ }^{70}$ Véase TAMARIT y LUQUE (2016), p. 82.

${ }^{71}$ Consúltese, DROST et al. (2015), p. 23.

${ }^{72}$ CHEON y REGEHR (2006), p. 388 ; BURKEMPER y BALSAM (2007), p. 128.
} 
escoger el sexo-. ${ }^{73}$ El trabajo previo llevado a cabo por los mediadores antes mencionado se identifica con los pre-encuentros o encuentros preparatorios que en algunos países de nuestro entorno se emplean en estos procesos de mediación; estos acostumbran a realizarse con ambas partes antes de ir a un encuentro común.

Junto a esto, pueden adoptarse medidas para evitar el tradicional cara a cara víctimaofensor. Es lo que se conoce como mediación indirecta, que comprende todo lo que no sea encuentro presencial directamente entre ambas partes en conflicto. Algunos de estos instrumentos consisten en que la víctima y el ofensor se reúnen primero cada uno con su mediador y después son estos, eventualmente acompañados por víctima y ofensor, los que se comunican en el encuentro común, como viene haciendo desde hace años el servicio Neustart de mediación austríaco. ${ }^{74}$ Mecanismos como la mediación subrogativa, en que la víctima interviene en la mediación con un ofensor, pero no con el que la victimizó, ${ }^{75}$ también podrían incluirse aquí. Incluso mejor, el empleo de las nuevas tecnologías, que abren la puerta al escenario de la mediación online ${ }^{76}$ podrían igualmente representar mecanismos muy adecuados, tanto para evitar el encuentro físico víctima-ofensor en las primeras fases, como para evitarlo en cualquier circunstancia en los casos en que el ofensor haya mostrado ser especialmente violento, manipulador o la víctima tema por su seguridad $^{77}$. Las videoconferencias, en salas específicas habilitadas al efecto, en que la víctima se hallase acompañada de un mediador, además eventualmente de una persona de su confianza, ofrecerían una real alternativa al encuentro cara a cara. Finalmente, nada impediría que las víctimas que en el caso concreto se consideren vulnerables - como podría suceder en algunos supuestos de violencia de género, pero también con víctimas ancianas o infantiles - se arbitrara un sistema en virtud del cual siempre se hallara presente en las sesiones como mínimo una persona de apoyo a la víctima, designada por esta o asignada, según los casos.

Para concluir, con el objeto de conjurar uno de los peligros denunciados en la aplicación de mecanismos de justicia restaurativa a casos de violencia de género, en el sentido de que pueden representar una "salida barata" para el maltratador acostumbrado a la construcción y a la solicitud del perdón como forma habitual de manipular a la víctima, deberían articularse mecanismos de monitorización del cumplimiento de los acuerdos. En caso de incumplimiento, deberían además preverse las consecuencias desfavorables que el mismo acarrearía para el ofensor.

El diseño de un programa de mediación que tuviese en cuenta algunas de las sugerencias aquí efectuadas, que no son más que las propuestas por la literatura

\footnotetext{
${ }^{73}$ DROST et al. (2015), p. 23.

${ }^{74}$ DROST et al. (2015), pp. 23-24.

75 Acerca de esta forma de mediación, véase BURKEMPER y BALSAM (2007), Pp 128-129.

${ }^{76}$ Ampliamente sobre las ventajas que el empleo de la mediación online, aunque aplicada a procesos por delitos sexuales, en que la implementación de mecanismos de resolución alternativa de conflictos también se ha discutido ampliamente, ROGERS (2009), pp. 349 y ss. Esta autora plantea la posibilidad de aplicar este tipo de mecanismos al programa Restore, el conocido programa de mediación en casos de violación activado en Estados Unidos por Mary P. Koos. Sin embargo, en p. 367, plantea que la ODR (online dispute resolution) puede constituir una real alternativa en casos de violencia doméstica con patrón de conducta violenta asentada.

77 MARTIN et al. (2010), p. 635, indican que la mediación online constituiría un mecanismo especialmente adecuado en tres grupos de casos: cuando las partes no residen en la misma zona, cuando el diálogo es factible, pero no lo es el encuentro, y finalmente el empleo de este método a modo de herramienta, es decir, para facilitar el acercamiento entre las partes hasta que se produzca el encuentro.
} 
especializada en el tema adaptadas a nuestra realidad, permitiría la aplicación de mecanismos de justicia restaurativa en casos de violencia de doméstica y de género. Su real efectividad, a la postre, únicamente podría confirmarse con la realización de las correspondientes evaluaciones periódicas de los programas implementados, conforme también se sugiere por parte de la literatura especializada ${ }^{78}$.

\footnotetext{
78 Acerca de la necesidad de monitorización de los programas de justicia restaurativa, vid, por todos, KURKI (2003), pp. 293 y ss.; LANDRUM (2010), pp. 464 y ss.
} 


\section{Bibliografía citada}

ACALE SÁNCHEZ, María (2006): La discriminación hacia la mujer por razón de género en el Código penal (Madrid, Reus).

ALONSO SALGADO, Cristina; TORRADO TARRÍO, Cristina (2011): "Violencia de género, justicia restaurativa y mediación”, en: CASTILLEJO MANZANARES, Raquel (dir.), Violencia de género, justicia restaurativa y mediación (Madrid, Wolters Kluwer), pp. 567-606.

ANGEL, Caroline M; SHERMAN, Lawrence W.; STRANG, Heather; ARIEL, Barak; BENNETT, Sarah; INKPEN, Nova; KEANE, Anne; RICHMOND, Therese S. (2014): "Short-term effects of restorative justice conferences on post-traumatic stress symptoms among robbery and burglary victims: a randomized controlled trial”, en: Journal of Experimental Criminology (Vol. 10, No 3), pp. 291-307.

ARNOLD, Gretchen; AKE, Jami (2013): "Reframing the Narrative of the Battered Women's Movement", en: Violence Against Women (Vol. 19, No 5), pp. 557578.

BARONA VILAR, Silvia (2011): Mediación Penal. Fundamentos, fines y régimen jurídico (Valencia, Tirant lo Blanch).

BELTRÁN MONTOLIU, Ana (2009): "Modelo de mediación en los Estados Unidos de América", en: BARONA VILAR, Silvia (Coord.), La mediación penal para adultos. Una realidad en los ordenamientos jurídicos (Experiencias en España, Inglaterra Gales, Países Escandinavos, Francia, Alemania, Portugal, Brasil y Chile), (Valencia, Tirant lo Blanch), pp. 53-84.

BRAIDOTTI, Rosi (2000): Sujetos nómades. Corporización y diferencia sexual en la teoría feminista contemporánea (Barcelona, Buenos Aires y México, Paidós).

BURFORD, Gale; PENNELL, Joan (1998): Family group decision making Project: Outcome Report (vols. 1-2) (St John's, NF, Memorial University of Newfoundland).

BURKEMPER, Bennett y BALSAM, Nina (2007): "Examining the use of restorative justice practices in domestic violence cases", en: Sant Luis University Public Law Review (Vol. 27, No 1), p. 121-134.

BUTLER, Judith (2007): El género en disputa: el feminismo y la subversión de la identidad (Barcelona, Buenos Aires y México, Paidós).

BUTTS, Thelma; GUILARTE GUTIÉRREZ, Patricia (2015): "Proyecto Plan formativo para derivación a mediación en la jurisdicción penal de adultos", Consejo General del Poder Judicial. Disponible en: http://www.poderjudicial.es/cgpj/es/Poder_Judicial [visitado el 25/10/2019].

CARMENA CASTRILLO, Manuela (2005): "Sobre por qué y para qué se hacen las leyes. Reflexiones ante la Ley Integral de Violencia de Género", en: Jueces Para la Democracia ( $\left.N^{\circ} 53\right)$, p. 29-38.

CASTILLEJO MANZANARES, Raquel; TORRADO TARRÍO, Cristina; ALONSO SALGADO, Cristina (2011): "Mediación en violencia de género", en: Revista de Mediación (Año 4, No 7), pp. 38-45.

CHEON, Aileen; REGEHR, Cheryl (2006): "Restorative justice models in cases of intimate partner violence: reviewing the evidence", en: Victims and Offenders (Vol. 1, No 4), pp. 369-394.

CONSEJO GENERAL DEL PODER JUDICIAL (2015a): "Datos resultantes de la mediación intrajudicial (año 2015)". Disponible en: http://www.poderjudicial.es/cgpj/es/Temas/Mediacion/Datos-mediacion- 
intrajudicial/Mediacion-intrajudicial-en-Espana--datos-2015 [visitado el 25/10/2019].

CONSEJO GENERAL DEL PODER JUDICIAL (2015b): "Guía para la práctica de la mediación intrajudicial”. Disponible en: http://www.poderjudicial.es/cgpj/es/Temas/Mediacion/Guia-para-la-practica-dela-Mediacion-Intrajudicial [visitado el 25/10/2019].

COUNCIL OF EUROPE (2011): "Explanatory Report to the Council of Europe Convention on preventing and combating violence against women and domestic violence". Disponible en: https://rm.coe.int/16800d383a [visitado el 25/10/2019].

CRENSHAW, Kimberle (1989): "Demarginalizing the Intersection of Race and Sex: A Black Feminist Critique of Antidiscrimination Doctrine, Feminist Theory and Antiracist Politics", en: The University of Chicago Legal Forum (Vol. 1989), pp. 139-167.

CRENSHAW, Kimberle (1991): "Mapping the Margins: Intersectionality, Identity Politics, and Violence Against Women of Color", en: Stanford Law Review (Vol. 43, No 6), pp. 1241-1299.

CURTIS-FAWLEY, Sarah; DALY, Kathleen (2005): "Gendered violence and restorative justice. The views of victim advocates", en: Violence Against Women (Vol. 11, No 5), pp. 603-638.

DALY, Kathleen; STUBBS, Julie (2007): "Feminist Theory, feminist and anti-racist politics, and restorative justice", en: JOHNSTONE, Gerry; VAN NESS, Daniel W (eds.), Handbook of Restorative Justice (Cullompton, Devon, Willan Publishing), pp. 149-170.

DE LAURETIS, Teresa (2000): Diferencias. Etapas de un camino a través del feminismo (Madrid, Horas y Horas).

DELEGACIÓN DEL GOBIERNO PARA LA VIOLENCIA DE GÉNERO (2015): "Macroencuesta de violencia contra la mujer 2015. Avance de resultados". Disponible http://www.violenciagenero.igualdad.mpr.gob.es/violenciaEnCifras/macroencue sta2015/home.htm [visitado el 25-01-2020].

DÍAZ LÓPEZ, Juan A. (2011); "Propuestas para la práctica de la mediación penal. Delitos patrimoniales cometidos entre parientes y responsabilidad penal de las personas jurídicas", en: Indret (3/2011), pp 1-50.

DROST, Lisanne; HALLER, Birgitt; HOFINGER, Veronika; VAN DER KOOIJ, Tinka; LÜNNEMANN, Katinka; WOLTHUIS, Annemieke (2015): "Restorative Justice in Cases of Domestic Violence. Best practice examples between increasing mutual understanding and awareness of specific protection needs. (JUST/2013/JPEN/AG/4587) WS1. Comparative Report". Disponible en: https://www.verwey-jonker.nl/publicaties/2015/restorative-justice-in-cases-ofdomestic-violence [visitado el 28/10/2019].

ESQUINAS VALVERDE, Patricia (2008): Mediación entre víctima y ofensor en la violencia de género (Valencia, Tirant lo Blanch).

ESQUINAS VALVERDE, Patricia (2010): "Capacitación de la mujer ("empowerment") y violencia de género", en: PUENTE ABA, Luz M. (dir.), La respuesta penal a la violencia de género. Lecciones de diez años de experiencia de una política criminal punitivista (Granada, Comares), pp. 323-342.

FERGUSON, Jean (2009): "Professional discretion and the use of restorative justice programs in appropriate domestic violence cases: an effective innovation", en: American University Criminal Law Brief (Vol. 4, No 2), pp. 3-22. 
FERNÁNDEZ LÓPEZ, María A. (2015): La Mediación en Procesos por Violencia de Género (Cizur Menor, Thomson Reuters-Aranzadi).

GELSTHORPE, Loraine (2012): "Violence against women: repairing harm through kith and kin", en: HARPER, Dee Wood; THORNTON, William E.; VOIGT, Lydia Y. (eds.), Violence: Do We Know It When We See It? A Reader (Durham-North Carolina, Carolina Academic Press), pp. 387-404.

GITTLEMAN, Andrea (2008): "Drawing the line. When to apply restorative justice to cases of violence against women". Disponible en: https://es.scribd.com/document/425256250/Gittleman2-authcheckdam [visitado el 28/10/2019].

GORDILLO SANTANA, Luis F. (2007): La justicia restaurativa y la mediación penal (Madrid, Iustel).

GUARDIOLA LAGO, María J. (2009): "La víctima de la violencia de género en el sistema de justicia y la prohibición de la mediación penal”, en: Revista General de Derecho Penal ( $\left.\mathrm{N}^{\mathrm{o}} 12\right)$, pp. 1-41.

HARAWAY, Donna. (1995): Ciencia, cyborgs y mujeres, la reinvención de la naturaleza (Madrid, Cátedra).

HEIM, Shannon M. (2011): "Revisions to Minnesota Domestic Violence Law Affords Greater Protection to Vulnerable Victims", en: William Mitchell Law Review (Vol. 37, No 2) pp. 950-970.

HERNÁNDEZ HIDALGO, Patricia (2017): Violencia de pareja: crítica victimológica a la respuesta del sistema de justicia penal (Valencia, Tirant lo Blanch).

HOPKINS, C. Quince; KOSS, Mary; BACHAR, Karen (2004): "Applying restorative justice to ongoing intimate violence, problems and possibilities", en: Sant Louis University Public Law Review (Vol. 23, № 1), pp. 289-311.

HOYLE, Carolyn (1998): Negotiating Domestic Violence. Police, Criminal Justice and Victims (Oxford, Claredon Press).

HOYLE, Carolyn; SANDERS, Andrew (2000): "Police Response to Domestic Violence. From Victim Choice to Victim Empowerment?", en: British Journal of Criminology (Vol. 40, No 1), pp. 14-36.

KOHN, Laurie S. (2010): "What's so funny about peace, love, and understanding? Restorative Justice as a new paradigm for domestic violence intervention", en: Selton Hall Law Review (Vol. 40, No 2), pp. 517-594.

KRIEGER, Sarah (2002): "The dangers of mediation in domestic violence cases", en: Cardozo Women's Law Journal (Vol. 8), pp. 235-270.

KURKI, Leena (2003): "Evaluating restorative justice practices", en: VON HIRSCH, Andrew; ROBERTS, Julian; BOTTOMS, Antony E.; ROACH, Kent y SCHIFF, Mara, (Eds.), Restorative Justice \& Criminal Justice. Competing or reconcilable paradigms? (Portland, Oregon, Hart Publishing), pp. 293-314.

LANDRUM, Susan (2010): "The ongoing debate about mediation in the context of domestic violence: a call for empirical Studies of mediation effectiveness", en: Cardozo Journal of Conflict Resolution (Vol. 12), pp. 425-471.

LARRAURI PIJOAN, Elena (2007a): "Justicia Restauradora y Violencia Doméstica", en Cursos de Derechos Humanos de Donostia-San Sebastian (Vol. 8), pp. 119136.

LARRAURI PIJOAN, Elena (2007b): Criminología crítica y violencia de género (Madrid, Trotta).

LATIMER, Jeff; DOWDEN, Craig; MUISE, Danielle (2005): "The effectiveness of restorative justice practices: a meta-analysis", en: The Prison Journal (vol. 85, N ${ }^{\circ}$ 2), pp. 127-144. 
LAURENZO COPELLO, Patricia (2005): "La violencia de género en la ley integral. Valoración político-criminal", en: Revista Electrónica de Ciencia Penal y Criminología ( $\mathrm{N}^{\mathrm{o}}$ 07-08), pp. 1-23.

LAURENZO COPELLO, Patricia (2008): "La violencia de género en Derecho penal. Un ejemplo de paternalismo punitivo", en: LAURENZO COPELLO, Patricia; MAQUEDA ABREU, María L. y RUBIO CASTRO, Ana M. (Coords.), Género, Violencia y Derecho (Valencia, Tirant lo Blanch), pp. 329-362.

LÜNNEMANN, Katinka; WOLTHUIS, Annemieke (2015): "Restorative Justice in Cases of Domestic Violence. Best practice examples between increasing mutual understanding and awareness of specific protection needs. Victim Offender Mediation: Needs of victims and offenders of Intimate Partner Violence. 2n comparative report, Interviews \& Focus Groups (JUST/2013/JPEN/AG/4587)". Disponible en: http://www.verwey-jonker.nl/publicaties/2015/restorative-justicein-cases-of-domestic-violence- [visitado el 28/10/2019].

MAQUEDA ABREU, María L. (2006): "La violencia de género. Entre el concepto jurídico y la realidad social", en: Revista Electrónica de Ciencia Penal y Criminología ( $\mathrm{N}^{\mathrm{o}}$ 08-02), pp. 1-13.

MAQUEDA ABREU, María L. (2010): “1989-2009: Veinte años de desencuentros entre la ley penal y la realidad de la violencia en la pareja", en: PUENTE ABA, Luz M. (dir.), La respuesta penal a la violencia de género. Lecciones de diez años de experiencia de una política criminal punitivista (Granada, Comares), pp.1-17.

MARTÍN, Jaume, CANO, Francisca; DAPENA, José (2010): "Justícia reparadora: mediació penal per adults i juvenil”, en: CASANOVAS, Pompeu; MAGRE, Jaume; LAUROBA, María E., Llibre Blanc de la Mediació a Catalunya (Barcelona, Generalitat de Catalunya-Departament de Justícia), pp. 587-646.

MARTIN, Paula. (1996): "Restorative Justice-A family violence perspective", en: Social Policy Journal of New Zealand ( $\mathrm{N}^{\mathrm{o}}$ 6), pp. 55-68.

MILLS, Linda G.; MALEY, Mary H.; SHY, Yael (2009): "Círculos de Paz and the promise of peace: restorative justice meets intimate violence", en: New York University Review of Law \& Social Change (Vol. 33, No 1), pp. 127-152.

MOHANTY, Chandra T. (2008a): "Bajo los ojos de Occidente: academia feminista y discursos coloniales", en: SUÁREZ NAVAZ, Liliana; HERNÁNDEZ CASTILlO, Rosalva A. (eds.), Descolonizando el feminismo. Teorías y prácticas desde los márgenes (Madrid, Cátedra), pp. 117-164.

MOHANTY, Chandra T. (2008b): "De vuelta a "Bajo los ojos de Occidente": la solidaridad feminista a través de las luchas anticapitalistas", en: SUÁREZ NAVAZ, Liliana; HERNÁNDEZ CASTILLO, Rosalva A. (Eds.), Descolonizando el feminismo. Teorías y prácticas desde los márgenes (Madrid, Cátedra), pp. 407-464.

MORRIS, Allison; GELSTHORPE, Loraine (2000): "Revisioning men's violence against their female partners", en: Howard Journal of Criminal Justice (Vol. 39, $\left.\mathrm{N}^{\circ} 4\right)$, pp. 412-428.

PELIKAN, Christa (2000): "Victim offender mediation in domestic violence cases. A research report". Disponible en: http://restorativejustice.org/10fulltext/pelikanchrista.-victim-offender-mediation-in-domestic-violence-cases-a-researchreport.html [visitado el 28/10/2019].

PELIKAN, Christa (2010): "On the efficacy of Victim-Offender-Mediation in cases of partnership violence in Austria, or: Men don't get better, but women get 
stronger: Is It still true?", en: European Journal of Criminal Policy and Research (Vol. 16, No 1), pp. 49-67.

PENNELL, Joan; BURFORD, Gale (2000): "Family group decision making: protecting children and women", en: Child Welfare (Vol. 79, No 2), pp. 131-158.

PENNELL, Joan; BURFORD, Gale (2002): "Feminist praxis: making family group conferencing work", en: STRANG, Heather; BRAITHWAITE, John (eds.), Restorative Justice and Family Violence (Cambridge, Cambridge University Press), pp. 108-127.

PRANIS, Kay (2002): "Restorative values and confronting family violence", en: STRANG, Heather; BRAITHWAITE, John (eds.), Restorative Justice and Family Violence (Cambridge, Cambridge University Press), pp. 23-41.

RAYE, Barbara E.; ROBERTS, Ann W. (2007): "Restorative Processes", en: JOHNSTONE, Gerry; VAN NESS, Daniel W (eds.), Handbook of Restorative Justice (Cullompton, Devon, Willan Publishing), pp. 211-227.

RIOS MARTIN, Julián Carlos; PASCUAL RODRIGUEZ, Ester; BIBIANO GUILLEN, Alfonso; SEGOVIA BERNABE, José Luis; LOZANO ESPINA, Francisca; ETXEBARRIA ZARRABEITIA, Xabier (2012): La mediación penal y penitenciaria. Experiencias de diálogo en el sistema penal para la reducción de la violencia y el sufrimiento humano (Madrid, Colex, $3^{\mathrm{a}}$ edición).

RODRÍGUEZ LAÍNZ, José L. (2011): "Mediación penal y violencia de género", en: Diario La Ley ( $\left.\mathrm{N}^{\mathrm{o}} 7557\right)$, pp. 1-11.

ROGERS, Sarah (2009): "Online Dispute Resolution: An option for mediation in the midst of gendered violence", en: Ohio State Journal on Dispute Resolution (Vol. 24, $\mathrm{N}^{\mathrm{o}} 2$ ), pp. 349-380.

SÁEZ, Ramón (dir.) (2010): “La mediación penal dentro del proceso. Análisis de situación. Propuestas de regulación y autorregulación. Protocolos de evaluación. Documento ideológico: análisis desde la perspectiva de la política criminal y del derecho a la tutela judicial efectiva", Consejo General del Poder Judicial. Disponible

en: http://www.poderjudicial.es/cgpj/es/Temas/Mediacion/Publicaciones/Mediacion -penal/ [visitado el 28/10/2019].

SCHIMMEL, Noam (2012): "The Moral Case for Restorative Justice as a Corollary of the Responsibility to Protect: A Rwandan Case Study of the Insufficiency of Impact of Retributive Justice on the Rights and Well-Being of Genocide Survivors", en: Journal of Human Rights (Vol. 11, No 2), pp. 161-188.

SECRETARÍA DE ESTADO DE IGUALDAD-DELEGACIÓN DEL GOBIERNO PARA LA VIOLENCIA DE GÉNERO (2018): "Violencia de Género. Boletín Estadístico Anual. Año 2018". Disponible en: http://www.violenciagenero.igualdad.mpr.gob.es/violenciaEnCifras/boletines/bo letinAnual/home.htm [visitado el 25-01-2020]

SECRETARÍA DE ESTADO DE IGUALDAD-DELEGACIÓN DEL GOBIERNO PARA LA VIOLENCIA DE GÉNERO (2019): "Documento refundido de medidas del Pacto de Estado en materia de Violencia de Género. Congreso+Senado". Disponible en: https://violenciagenero.igualdad.gob.es/pactoEstado/docs/Documento_Refundid o_PEVG_2.pdf [visitado el 28/10/2019].

SHAPLAND, Joanna; ATKINSON, Anne; ATKINSON, Hellen; CHAPMAN, Becca; DIGNAN, James; HOWES, Marie; JOHNSTONE, Jennifer; ROBINSON, Gwen; SORSBY, Angela (2007): "Restorative justice: the views of victims and offenders. The third report from the evaluation of three schemes", Ministry of 
Justice Research Series 3/07. Disponible en: http://crjc.ca/wpcontent/uploads/Restorative-Justice-the-Views-of-Victims-and-Offenders.pdf [visitado el 25/10/2019].

SHERMAN, Lawrence W. (1992): Policing Domestic Violence. Experiments and Dilemmas (New York, The Free Press).

SHERMAN, Lawrence W. (2000): "Domestic violence and restorative justice: answering key questions", en: Virginia Journal of Social Policy \& the Law, (Vol. 8, No 1), pp. 263-289.

SHERMAN, Lawrence. W.; STRANG, Heather (2007): "Restorative Justice: the evidence", The Smith Institute. Disponible en: https://www.iirp.edu/pdf/RJ_full_report.pdf [visitado el 25/10/2019].

SOKOLOFF, Natalie J.; DUPONT, Ida (2005): "Domestic Violence at the Intersections of Race, Class, and Gender. Challenges and Contribution to Understanding Violence Against Marginalized Women in Diverse Communities", en: Violence Against Women (Vol 11, No 1), pp. 38-64.

SPYVAK, Gayatri G. (2010): Crítica a la razón postcolonial. Hacia una crítica del presente evanescente (Madrid, Akal).

STUBBS, Julie (2002): “Domestic violence and women's safety: feminist challenges to restorative justice", en: STRANG, Heather; BRAITHWAITE, John (Eds.), Restorative Justice and Family Violence (Cambridge, Cambridge University Press), pp. 42-61.

STUBBS, Julie (2007); "Beyond apology? Domestic violence and critical questions for restorative justice", en: Criminology \& Criminal Justice (Vol. 7, No 2), pp. 169187.

STUBBS, Julie (2010): "Relations of domination and subordination: challenges for restorative justice in responding to domestic violence", en: University of New South Wales Law Journal (Vol. 33, No 3), pp. 970-986.

TAMARIT SUMALLA, Josep M. (2015): "La reparación y el apoyo a las víctimas", en: TAMARIT SUMALLA, Josep M. (Coord.), VILLACAMPA ESTIARTE, Carolina; SERRANO MASIP, Mercedes, El Estatuto de las víctimas de delitos. Comentarios a la Ley 4/2015 (Valencia, Tirant lo Blanch), pp. 305-354.

TAMARIT, Josep; LUQUE, Eulalia (2016): "Can restorative justice satisfy victims' needs? Evaluation of the Catalan victim-offender mediation programme", en: Restorative Justice. An international Journal (Vol. 4, No 1), pp. 68-85.

UMBREIT, Mark S., COATES, Robert B.; VOS, Betty (2004): "Victim-offender mediation: three decades of practice and research", en: Conflict Resolution Quarterly (Vol. 22, No 1-2), pp. 279-303.

UMBREIT, Mark S. Y VOS, Betty (2000): "Homicide Survivors Meet the Offender Prior to Execution: Restorative Justice through Dialogue", en: Homicide Studies (Vol. 4, No 1), pp. 63-87.

UMBREIT, Mark S., VOS, Betty, COATES, Robert B.; LIGHTFOOT, Elisabeth (2007): "Restorative justice: an empirically grounded movement racing many opportunities and pitfalls", en: Cardozo Journal of Conflict Resolution (Vol. 8) pp. 511-564.

VARONA MARTÍNEZ, Gema (2008): "Evaluación externa de la actividad del servicio de mediación penal de Barakaldo (julio-diciembre de 2007)". Disponible en: https://www.euskadi.eus/gobiernovasco/contenidos/informacion/mediacion_penal/es_smp/adjuntos/IVACKREI\%20Evaluaci\%C3\%B3n\%202007\%20SMP\%20Barakaldo.2.pdf [visitado el 28/10/2019]. 
VARONA MARTÍNEZ, Gema (2009): “Justicia restaurativa a través de los servicios de mediación penal en Euskadi. Evaluación externa de su actividad (octubre 2008septiembre 2009)". Disponible en: https://www.ehu.eus/documents/1736829/2153076/Justicia+restaurativa+a+trave s+de+los+servicios+de+mediacion+penal.pdf [visitado el 28/10/2019].

VÁZQUEZ-PORTOMEÑE SEIJAS, Fernando (2013): "Posibilidades y límites de aplicación de la mediación penal en casos de violencia de género", en: RODRÍGUEZ CALVO, María S.; VÁZQUEZ-PORTOMEÑE SEIJAS, Fernando, La violencia de género. Aspectos médico-legales y jurídico-penales (Valencia, Tirant lo Blanch), pp. 311-332.

VILLACAMPA ESTIARTE, Carolina (2012); "Justicia restaurativa aplicada a supuestos de violencia de género", en: Revista Penal (Nº 30), pp. 177-216.

VILLACAMPA ESTIARTE, Carolina (Coord.), CEREZO DOMINGUEZ, Ana Isabel; GÓMEZ GUTIÉRREZ, Mar (2019): Introducción a la Victimología (Madrid, Síntesis).

WALKER, Rebecca (1992): "Becoming the Third Wave", en: Ms. Magazine (Vol. 11, No 2), pp. 39-41.

WALTERS, Mark Austin (2015): “I Thought “He's a Monster”... [But] He Was Just... Normal: Examining the Therapeutic Benefits of Restorative Justice for Homicide", en: British Journal of Criminology (Vol. 55, No 6), pp. 1207-1225.

WEMMERS, Jo-Anne; CYR, Katie (2005): "Can mediation be therapeutic for crime victims? An evaluation of victim's experiences in mediation with young offenders", en: Canadian Journal of Criminology and Criminal Justice (Vol. 47, No 3), pp. 527-544.

\section{Normas Jurídicas Citadas}

Ley Orgánica 1/2004, de 28 de diciembre, de Medidas de Protección Integral contra la Violencia de Género. Boletín Oficial del Estado, núm. 313, de 29 de diciembre de 2004.

Convenio del Consejo de Europa sobre prevención y lucha contra la violencia contra las mujeres y la violencia doméstica (Estambul, 11 mayo 2011). Instrumento de ratificación: Boletín Oficial del Estado, núm. 137, de 6 de junio de 2014.

Directiva 2012/29/UE del Parlamento Europeo y del Consejo, de 25 de octubre de 2012, por la que se establecen normas mínimas sobre los derechos, el apoyo y la protección de las víctimas de delitos, y por la que se sustituye la Decisión marco 2001/220/JAI del Consejo. Diario Oficial de la Unión Europea, L 315, de 14 de noviembre de 2012.

Ley 4/2015, de 27 de abril, del Estatuto de la Víctima del Delito. Boletín Oficial del Estado, núm. 101, de 28 de abril de 2015.

Real Decreto 1109/2015, de 11 de diciembre, por el que se desarrolla la Ley 4/2015, de 27 de abril, del Estatuto de la Víctima del Delito, y se regulan las Oficinas de Asistencia a las Víctimas del Delito. Boletín Oficial del Estado, núm. 312, de 30 de diciembre de 2015. 